\title{
NEUROPSYCHOPHARMACOLOGY REVIEWS Alcohol use disorder and sleep disturbances: a feed-forward allostatic framework
}

\author{
George F. Koob ${ }^{1,2}$ and lan M. Colrain ${ }^{3,4}$
}

The development of alcohol use disorder (AUD) involves binge or heavy drinking to high levels of intoxication that leads to compulsive intake, the loss of control in limiting intake, and a negative emotional state when alcohol is removed. This cascade of events occurs over an extended period within a three-stage cycle: binge/intoxication, withdrawal/negative affect, and preoccupation/ anticipation. These three heuristic stages map onto the dysregulation of functional domains of incentive salience/habits, negative emotional states, and executive function, mediated by the basal ganglia, extended amygdala, and frontal cortex, respectively. Sleep disturbances, alterations of sleep architecture, and the development of insomnia are ubiquitous in AUD and also map onto the three stages of the addiction cycle. During the binge/intoxication stage, alcohol intoxication leads to a faster sleep onset, but sleep quality is poor relative to nights when no alcohol is consumed. The reduction of sleep onset latency and increase in wakefulness later in the night may be related to the acute effects of alcohol on GABAergic systems that are associated with sleep regulation and the effects on brain incentive salience systems, such as dopamine. During the withdrawal/negative affect stage, there is a decrease in slow-wave sleep and some limited recovery in REM sleep when individuals with AUD stop drinking. Limited recovery of sleep disturbances is seen in AUD within the first 30 days of abstinence. The effects of withdrawal on sleep may be related to the loss of alcohol as a positive allosteric modulator of $\mathrm{GABA}_{\mathrm{A}}$ receptors, a decrease in dopamine function, and the overactivation of stress neuromodulators, including hypocretin/orexin, norepinephrine, corticotropin-releasing factor, and cytokines. During the preoccupation/anticipation stage, individuals with AUD who are abstinent long-term present persistent sleep disturbances, including a longer latency to fall asleep, more time awake during the night, a decrease in slow-wave sleep, decreases in delta electroencephalogram power and evoked delta activity, and an increase in REM sleep. Glutamatergic system dysregulation that is observed in AUD is a likely substrate for some of these persistent sleep disturbances. Sleep pathology contributes to AUD pathology, and vice versa, possibly as a feed-forward drive to an unrecognized allostatic load that drives the addiction process.

Neuropsychopharmacology (2020) 45:141-165; https://doi.org/10.1038/s41386-019-0446-0

\section{INTRODUCTION}

Sleep is a ubiquitous complex behavior that is necessary to sustain mental and physical health in humans. The different states of sleep and transitions between sleep and wakefulness are supported by a complex set of patterns of neurological activation and neurotransmitter release [1]. Many of the neurotransmitters and brain systems that are known to be involved in sleep-wake regulation are also affected by alcohol (e.g., [2-4]). Thus, unsurprisingly, alcohol affects sleep in several ways. Acute intoxication can alter sleep, but the effects of alcohol show tolerance with repeated use and dependence $[5,6]$. This tolerance is accompanied by adaptations of several neurotransmitter systems, either by modulating their release or modifying the sensitivity of their response mechanisms [7-10]. Withdrawal from alcohol in dependent individuals can be associated with neurological manifestations of a consequent neurochemical imbalance [5]. Over time, recovery can occur to restore a normal balance of inhibitory and excitatory systems, but some changes that are induced by alcohol may be resistant to restoration. The present review attempts to conceptually place the published literature that is relevant to the above factors into a three-stage cycle framework: binge/intoxication, withdrawal/negative affect, and preoccupation/anticipation ("craving").

Notably, several decisions were made with regard to which data are reviewed herein and the ways in which they are presented in the review. First, the salience of having sleep interrupted by periods of wakefulness is a potential driver of behavior. Therefore, the percentage of wakefulness after sleep onset (WASO\%) is reported rather than the more typical inverse measure of sleep efficiency (i.e., the percentage of time in bed spent asleep). Second, wake and sleep stage data are reported as percentages of sleep time throughout the review. This is used rather than absolute time spent in each state because of differences between studies in amounts of time that are available for sleep, the age of the subjects, and other factors that can influence absolute time values. Third, wherever possible, data are presented as difference scores to normalize data across experiments. This helps address issues that are related to the fact that the studies that are reported herein were published over a period of more than four decades. Over this time, dramatic changes in recording technology have

\footnotetext{
${ }^{1}$ National Institute on Alcohol Abuse and Alcoholism, National Institutes of Health, 6700B Rockledge Drive, Room 1209, MSC 6902, Bethesda, MD 20892-6902, USA; ${ }^{2}$ National

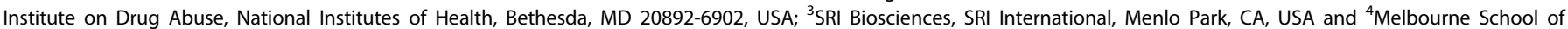
Psychological Sciences, The University of Melbourne, Melbourne, Australia

Correspondence: George F. Koob (george.koob@nih.gov)
}

Received: 12 April 2019 Revised: 9 June 2019 Accepted: 13 June 2019

Published online: 24 June 2019 


\begin{tabular}{|c|c|c|}
\hline & Definition & EEG characteristics \\
\hline Wake & Clear evidence of conscious wakefulness. & $\begin{array}{l}\text { alpha }(8-12 \mathrm{~Hz}) \text {, beta }(13-30 \mathrm{~Hz}) \text {, and gamma } \\
(>30 \mathrm{~Hz})\end{array}$ \\
\hline N1 & Waxing and waning of consciousness. Drowsiness. & alpha or beta alternating with theta $(4-7 \mathrm{~Hz})$ \\
\hline N2 & Clear sleep with the presence of sleep spindles and K-complexes. & theta and some delta $(<4 \mathrm{~Hz})$ \\
\hline N3 & Clear sleep, largely dominated by large slow voltage fluctuations. & prominent delta with some theta \\
\hline REM & $\begin{array}{l}\text { Rapid-eye-movement sleep with saccadic eye movements and lower } \\
\text { muscle tone. }\end{array}$ & Mixture of beta and theta \\
\hline NREM & Non-rapid-eye-movement sleep. Combination of stages N1, N2, and N3. & theta and delta \\
\hline SWS & Slow-wave-sleep (now termed N3). & prominent delta with some theta \\
\hline SWA & Slow wave activity, a measure of slow-frequency EEG power. & delta \\
\hline $\begin{array}{l}\text { Sleep } \\
\text { spindle }\end{array}$ & Brief $(0.5-1 \mathrm{~s})$ bursts of oscillatory EEG. & sigma $(12-16 \mathrm{~Hz})$ \\
\hline K-complex & Single high-amplitude EEG waveform with a duration of approximately 1 & delta \\
\hline
\end{tabular}

occurred, spanning the initial acceptance of consensus scoring rules for sleep stages [11] and gradual shifts in those rules and the ways in which they are applied [12]. If earlier papers tend to overor underreport slow-wave sleep (SWS) or rapid-eye-movement (REM) sleep, then the values of interest are normalized to appropriate within-subject or between-group control data that should have the same issue. Finally, several papers in the past have highlighted REM latency or some measure of the intensity of eye movements in REM as distinguishing features of sleep in alcoholics [5]. Although these measures are indeed interesting, we have chosen to focus on the percentage of REM as a key measure in this review. This decision was based on the practical consideration that many more papers report REM\% than the other measures.

The term Alcohol Use Disorder (AUD) is used throughout the manuscript, but this specific diagnosis is a relatively recent concept. Many of the studies that are cited herein used other diagnoses, such as "alcohol abuse" or "alcohol dependence" or even "alcoholism," based on various research or clinical definitions that were available at the time the research was conducted.

\section{DIAGNOSTIC FEATURES: DEFINITIONS AND CONCEPTUAL FRAMEWORK OF ALCOHOL USE DISORDER}

In AUD, a pattern of oral drug taking evolves that is often characterized by binges of alcohol intake that can be daily episodes or prolonged days of heavy drinking and is characterized by a severe emotional and somatic withdrawal syndrome. Many individuals with AUD continue with such a binge/withdrawal pattern for extended periods of time, but some individuals evolve into a situation in which they must have alcohol available at all times to avoid the negative consequences of abstinence. Here, intense preoccupation with obtaining alcohol (craving) develops that is linked not only to stimuli that are associated with obtaining the drug but also to stimuli that are associated with withdrawal and the aversive motivational state. A pattern ultimately develops in moderate to severe AUD in which the drug must be taken to avoid the severe dysphoria and discomfort of abstinence.

Alcohol use disorder can be defined as a chronically relapsing disorder that is characterized by a compulsion to seek and take the drug (alcohol), loss of control in limiting drug (alcohol) intake, and the emergence of a negative emotional state (e.g., dysphoria, anxiety, irritability, and hyperkatifeia), reflecting a motivational withdrawal syndrome, when access to the drug (alcohol) is prevented. These key elements incorporate most of the symptoms of AUD as expressed in moderate to severe AUD in the Diagnostic and Statistical Manual of Mental Disorders, 5th edition (DSM-5) [13].
The diagnostic criteria for AUD and addiction in general, as described in the DSM, have evolved from the first edition that was published in 1952 [14] to the current DSM-5 [13], with a shift from an emphasis on the criteria for tolerance and withdrawal to other criteria that are more directed toward compulsive use. In the DSM-5 [13], the new diagnostic criteria for addiction merged the abuse and dependence constructs (i.e., substance abuse and substance dependence) into one continuum that defines "alcohol use disorder" on a range of severity, from mild to moderate to severe, based on the number of criteria that are met out of 11 criteria.

Alcohol use disorder and addiction in general have been heuristically framed as a three-stage cycle: binge/intoxication, withdrawal/negative affect, and preoccupation/anticipation ("craving") [15] (Fig. 1). These three stages represent dysregulation in three functional domains (incentive salience/pathological habits, negative emotional states, and executive function, respectively). While formulated as a heuristic framework, a study that was designed to identify the domains that drive addiction based on a factor analysis of a deeply phenotyped clinical sample using a broad range of human testing scales and neuropsychological tests supported the existence of incentive salience, negative emotionality, and executive function as domains that are relevant to AUD $[16,17]$.

As originally described, the cycle of addiction was hypothesized to reflect a spiral of self-regulation pathology and increasing motivation for compulsive drug seeking [15]. Motivation that drives the initial drug seeking from positive reinforcement was argued to shift to an additional source of motivation that drives continued drug seeking from negative reinforcement [18]. Negative reinforcement can be defined as the process by which the removal of an aversive stimulus (e.g., negative emotional state of drug withdrawal) increases the probability of a response (e.g., dependence-induced drug intake to relieve the negative emotional state). Driving negative reinforcement is a negative emotional state that is a common presentation in most individuals with AUD during withdrawal and protracted abstinence. Importantly, negative reinforcement is not punishment, although both involve an aversive stimulus. In punishment, the aversive stimulus suppresses behavior, including drug taking (e.g., disulfiram [Antabuse]). Negative reinforcement can also be considered reinforcement via relief, such as by removal of the negative emotional state of acute withdrawal or protracted abstinence.

The three domains are hypothesized to be mediated by three major neurocircuitry elements (basal ganglia, extended amygdala, and prefrontal cortex, respectively) $[19,20]$ (Fig. 1). The three 


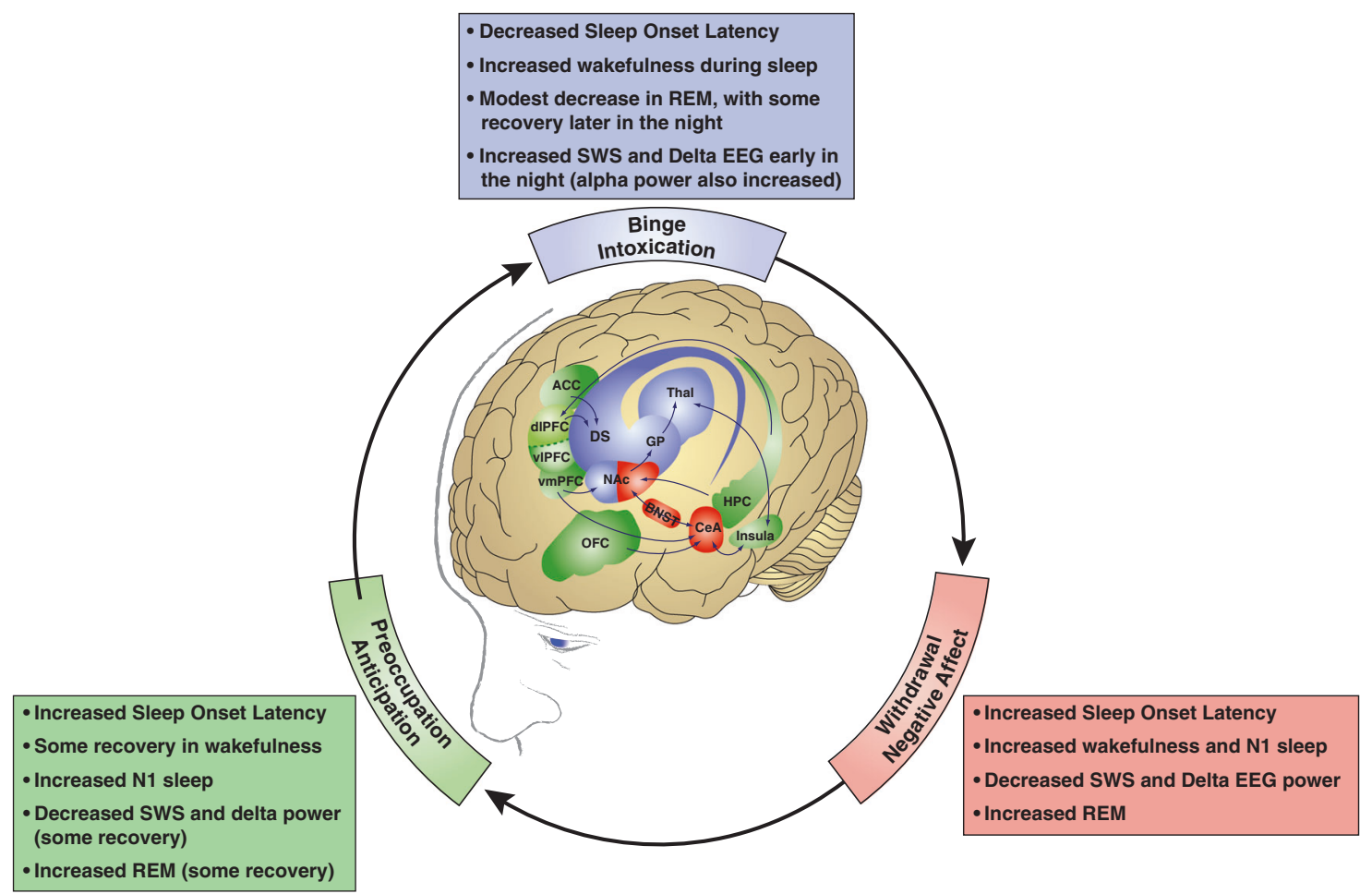

Fig. 1 Sleep dysregulation during alcohol addiction incorporated into the three-stage conceptual framework for the neurobiological basis of addiction. In the binge/intoxication stage, reinforcing effects of drugs may engage reward neurotransmitters and associative mechanisms in the nucleus accumbens shell and core and then engage stimulus-response habits that depend on the dorsal striatum. Two major neurotransmitters that mediate the rewarding effects of drugs of abuse are dopamine and opioid peptides. In the withdrawal/negative affect stage, the negative emotional state of withdrawal may engage activation of the extended amygdala. The extended amygdala is composed of several basal forebrain structures, including the bed nucleus of the stria terminalis, central nucleus of the amygdala, and possibly a transition zone in the medial portion (or shell) of the nucleus accumbens. Major neurotransmitters in the extended amygdala that are hypothesized to function in negative reinforcement are corticotropin-releasing factor, norepinephrine, and dynorphin. There are major projections from the extended amygdala to the hypothalamus and brainstem. The preoccupation/anticipation (craving) stage involves the processing of conditioned reinforcement in the basolateral amygdala and the processing of contextual information by the hippocampus. Executive control depends on the prefrontal cortex and includes the representation of contingencies, the representation of outcomes, and their value and subjective states (i.e., craving and, presumably, feelings) that are associated with drugs. The subjective effects, termed "drug craving" in humans, involve activation of the orbitofrontal and anterior cingulate cortices and temporal lobe, including the amygdala. A major neurotransmitter that is involved in the craving stage is glutamate that is localized in pathways from frontal regions and the basolateral amygdala that project to the ventral striatum. ACC, anterior cingulate cortex; BNST, bed nucleus of the stria terminalis; CeA, central nucleus of the amygdala; DS, dorsal striatum; dIPFC, dorsolateral prefrontal cortex; GP, globus pallidus; HPC, hippocampus; NAC, nucleus accumbens; OFC, orbitofrontal cortex; Thal, thalamus; vIPFC, ventrolateral prefrontal cortex; vmPFC, ventromedial prefrontal cortex. Modified from [19]

stages are conceptualized as interacting with each other, becoming more intense, and ultimately leading to the pathological state that is known as addiction [15].

Derived largely from fundamental work in neurobiology, the thesis argued herein is that AUD is a brain neurocircuitry disorder and that neuroadaptations within specific motivational circuits play an important role in defining and perpetuating the disorder. As formulated, the excessive engagement of reward circuitry engages high incentive salience for cues and contexts that are conditioned to drug seeking (binge/intoxication stage) and drives pathological habits. These functional changes in reward and habit circuits set up a series of neuroadaptations that involve core deficits of lower reward function and the greater activation of brain stress systems (withdrawal/negative affect stage) and significant impairment in executive function, all of which contribute to the compulsive drinking that is associated with AUD (Fig. 1).

For the binge/intoxication stage, several major neurotransmitter systems (e.g., $Y$-aminobutyric acid [GABA], glutamate, endogenous opioids, and dopamine) converge on the nucleus accumbens for the intoxicating and incentive salience effects of alcohol and glutamate and dopamine in the basal ganglia for the development of pathological habits [21].
In the neurocircuitry and neuropharmacology of the withdrawal/negative affect stage, the persistent increase in motivation that is associated with dependence in addiction $[22,23]$ is conceptualized as a cycle of the increasing dysregulation of brain reward/anti-reward mechanisms that results in a negative emotional state that contributes to the compulsive use of drugs. This negative emotional state in AUD has been hypothesized to be driven not only by the loss of reward function that is mediated by GABA, endogenous opioids, and dopamine but also by a gain in brain stress neurotransmitter system function (e.g., corticotropinreleasing factor [CRF], norepinephrine, hypocretin, and dynorphin) and neuroimmune function, all of which converge on parts of the extended amygdala, including elements of the nucleus accumbens) $[20,21]$. There are also anti-stress, "buffer" neuromodulatory systems that also converge on the extended amygdala (e.g., neuropeptide $\mathrm{Y}$ [NPY], nociceptin, endocannabinoids, and oxytocin) that may be compromised during the development of alcohol addiction, also contributing to the malaise of acute and protracted withdrawal $[20,24]$.

The neurocircuitry that drives the preoccupation/anticipation or "craving" stage of the addiction cycle is hypothesized to mediate relapse in humans not only by the constructs of impulsivity and compulsivity but also by elements that define protracted 
abstinence and craving. Human imaging studies have revealed neurocircuitry dysregulation during the preoccupation/anticipation stage in AUD that includes compromises in frontal cortical executive function and the dysregulation of substrates that mediate craving. Lower frontal cortex activity parallels deficits in executive function in neuropsychologically challenging tasks in AUD [25], and deficits in executive function (e.g., response disinhibition, expectations, and impulsivity) have been linked to craving in addiction [26]. Neurotransmitter systems that are involved in craving in animal models of cue-induced reinstatement have primarily focused on a glutamatergic projection from the frontal cortex and basolateral amygdala to the nucleus accumbens [27].

\section{MAPPING THE NEUROSCIENCE MODEL OF ADDICTION ONTO SLEEP: ALCOHOL INTERACTIONS}

Human sleep is defined on the basis of changes in electroencephalographic (EEG) activity, augmented by measurements of eye movements and postural muscle tone to aid in the differentiation of REM sleep from wakefulness. There is a continuum of predominant EEG frequencies from wakefulness through REM sleep to deep SWS. Wakefulness is associated with very high frequency gamma oscillations $(\geq \sim 40 \mathrm{~Hz})$ and desynchronized beta activity $(\sim 20-30 \mathrm{~Hz})$. Relaxed wakefulness, especially when the eyes are closed prior to sleep, is associated with synchronized alpha oscillations $(\sim 10 \mathrm{~Hz})$ that are predominant at occipital scalp sites. This gives way to slower, mixed-frequency theta activity $(4-7 \mathrm{~Hz})$ in stage 1 , light non-REM (NREM) sleep (N1) [12], although N1 is characterized by drowsiness with the waxing and waning of consciousness that maps onto the waxing and waning of alpha (consciousness) and theta (unconscious) activity. REM sleep, constituting $20-25 \%$ of the night, exhibits desynchronized activity in the theta and beta ranges, reflecting the partial reactivation of brainstem mechanisms that are fully active in wakefulness and deactivated in NREM sleep. Stage 2 NREM sleep (N2) is characterized by theta activity, some delta activity $(0.3-2$ $\mathrm{Hz}$ ), phasic sleep spindles (synchronized sigma activity: $12-16 \mathrm{~Hz}$ ), and K-complexes (high-amplitude single delta waves) and constitutes between $45-55 \%$ of the night. Stage 3 and 4 NREM sleep (N3 or SWS) is characterized by slow delta activity that comprises $\sim 18 \%$ of the night. NREM and REM sleep alternate across the night in $\sim 90-$ min cycles. As the sleep episode progresses, Stage 2 sleep accounts for most NREM sleep, and the amount of REM sleep increases.

Acute effects of alcohol on sleep: binge/intoxication domain Alcohol's sedative actions on the central nervous system (CNS) can lead to sleepiness and sleep. The impact of acute alcohol ingestion prior to sleep can be reasonably assumed to vary, based on a number of factors, including blood alcohol levels at sleep onset, the time of the last drink relative to sleep onset, the time taken to metabolize alcohol and eliminate it and its major metabolites, age, sex, and body fat percentage. The metabolism of alcohol by liver enzymes is unaffected by sleep [28]. Thus, over the duration of an extended period of sleep, blood levels of alcohol and major metabolites (e.g., acetaldehyde and acetate) vary substantially and are expected to impact sleep differently at different points in the sleep cycle. Given the pharmacokinetics of alcohol absorption, blood alcohol levels may continue to rise during sleep if alcohol is consumed immediately prior to sleep onset but will eventually fall after metabolism and elimination, according to the pharmacokinetics that are provided by the status of liver function and genetic factors in the production of liver enzymes [29]. In addition to the direct effect of alcohol and metabolites on sleep and possible early withdrawal opponent processes, it is also necessary to consider more prosaic secondary effects, such as diuresis, on sleep disturbances.
A key interrelationship between alcohol intoxication and sleep is its potential to generate erroneous beliefs about alcohol as an effective self-administered therapy for insomnia [30, 31]. There is, however, only a small body of literature that reports laboratory investigations of the ways in which acute intoxication impacts sleep. Results have varied between studies because of typical sources of variance in human physiology experiments, such as small sample sizes, the lack of consistency in dosing schedules and amounts, and the gender and age distributions of the subject populations.

Acute effects of alcohol on sleep: time to fall asleep and wakefulness after sleep onset

Sleep is a rapidly reversible unconscious state. However, beliefs about how substances or behaviors influence sleep quality are based on conscious experience, either how a person feels the next day (e.g., sleepy/rested, good/bad mood, etc.) or their remembered experience of wakeful consciousness around the sleep period (e.g., time taken to fall asleep, time spent awake during the night, etc.). Thus, such measures as sleep onset latency, time spent awake after sleep onset, and sleep efficiency (time asleep/time in bed) based on the perception that alcohol accelerates sleep onset are more salient in terms of developing and reinforcing beliefs than measures of REM sleep or SWS or how much delta EEG power is generated during the sleep period. Several studies have used non-intoxicating doses of alcohol. Reviews of these data can be found in Colrain et al. [5] and Ebrahim et al. [6].

Table 1 summarizes sleep onset latency (SOL) data, typically measured as the time from lights out to the onset of stage 1 (N1) sleep, taken from studies that either had a single night of alcohol administration, or in the first night of several nights [28, 32-42]. The average SOL for the no-dose nights in studies of rested, healthy controls was around 15 min across studies. Intoxicating doses of alcohol appear to lead to a modest reduction of SOL by $\sim 5 \mathrm{~min}$ at doses $\geq 0.9 \mathrm{~g} / \mathrm{kg}$. Although this effect may seem small, even zolpidem (i.e., arguably the current gold standard pharmacological treatment for insomnia) sometimes shows effects of similar magnitude when administered to healthy controls $[43,44]$.

Another sleep variable with high salience is the number of minutes spent awake after sleep onset (WASO). Table 2 shows WASO data from a number of studies that split the night into early and later periods [28, 32, 33, 38, 39, 41, 42] to separate high blood alcohol levels early in the night from falling blood alcohol levels, but also possibly still high metabolite levels later in the night. Data from whole night studies show a small increase in WASO with high alcohol doses. Data from split night studies show a tendency toward a decrease in WASO in the first half of the night following intoxicating doses of alcohol but an increase in the second half of the night, with a similar effect magnitude regardless of the intoxicating dose that is administered. Other sleep continuity variables, such as the number of awakenings and sleep efficiency (i.e., minutes asleep as a proportion of time in bed), show similar trends [39, 42]. Supplementary Table S1 shows data from studies that reported across the entire night [32, 34$40,45]$. Notably, in two studies, Roehrs and colleagues showed increases in WASO with alcohol in insomnia patients [37] and in controls who had restricted sleep on the prior night [36]. Thus, even in cases in which prior sleep is poor, the net effect of an intoxicating alcohol dose is to worsen sleep by increasing WASO.

There is one other study worth noting [46] that differs from those reviewed above, in which alcohol was consumed in the afternoon, $6 \mathrm{~h}$ before bedtime. The $0.55 \mathrm{~g} / \mathrm{kg}$ dose of vodka that was administered to subjects led to an initial breath alcohol level of $0.08 \mathrm{~g} \%$, which decreased to zero before sleep onset. No difference in sleep onset latency was found between control and alcohol nights, but WASO substantially increased on alcohol nights (66.9 vs. $38.7 \mathrm{~min}$ ), and the effect was maximal later in the night. The data confirm the general trend of the other studies, in which 
Table 1. Sleep onset latency (minutes) in studies that compared a no-dose (placebo or no alcohol) night to nights in which different doses of alcohol were administered prior to bed

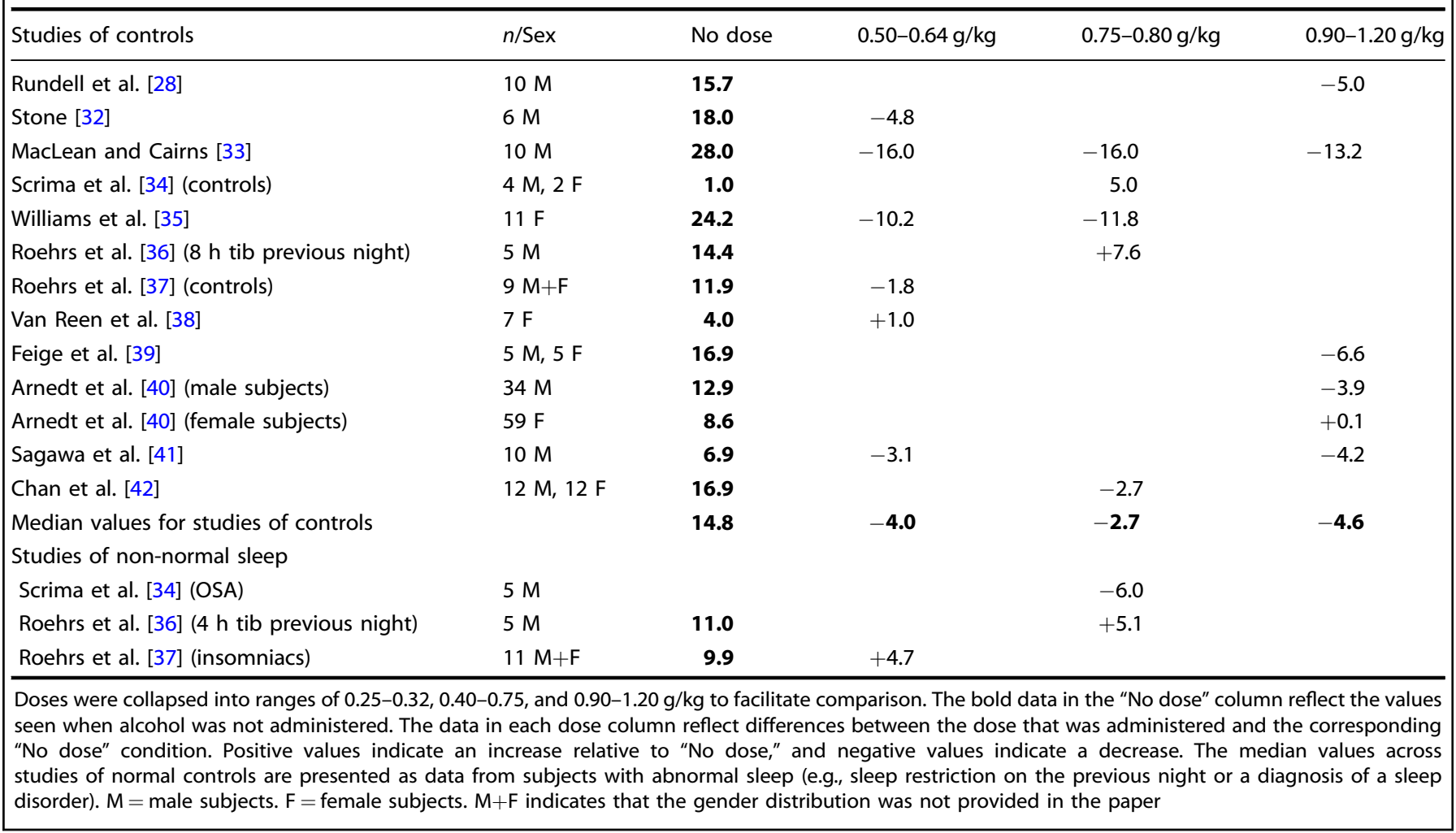

the effects on SOL are probably attributable to alcohol, and the effects on WASO are attributable to neuroadaptations to alcohol or the presence of alcohol metabolites.

In summary, the acute effects of alcohol on the time taken to fall asleep are highly variable, even at high alcohol doses. The amount of time spent awake during the sleep period tends to decrease early in the night and then increase later in the night when high doses of alcohol are administered prior to bed, leading to an overall increase across the night. Therefore, somewhat paradoxically, despite alcohol's sedative effects and the strongly held societal beliefs about its efficacy as a sleep aid, although the time taken to fall asleep decreases modestly, the amount of time spent awake during the night increases following the consumption of intoxicating levels of alcohol prior to bedtime.

\section{Binge/intoxication: effects on REM sleep}

The consensus view in the literature is that alcohol suppresses REM sleep, with a rebound increase in REM sleep that occurs when blood alcohol levels decrease. For the first half of the night (Table 3), relative to the no-alcohol condition, studies that administered $0.50-0.64 \mathrm{~g} / \mathrm{kg}$ alcohol reported a median $0.7 \%$ increase in REM as a percentage of sleep time. Studies that administered $0.75-0.80 \mathrm{~g} / \mathrm{kg}$ alcohol reported a median $6.7 \%$ decrease, and studies that administered $0.90-1.2 \mathrm{~g} / \mathrm{kg}$ alcohol reported a median $2.6 \%$ decrease. There is some evidence of rebound in the second half of the night, other than when the highest doses of alcohol were used. In the second half of the night, relative to the no-alcohol condition, studies that administered $0.50-0.64 \mathrm{~g} / \mathrm{kg}$ alcohol reported a median $5 \%$ increase in REM as a percentage of sleep time. Studies that administered $0.75-0.80 \mathrm{~g} / \mathrm{kg}$ alcohol reported a median $6.5 \%$ increase, but studies that administered $0.90-1.2 \mathrm{~g} / \mathrm{kg}$ alcohol reported a median $2.1 \%$ decrease. Intoxicating doses of alcohol, however, show variable results when data are collapsed over the entire night
(Supplementary Table S2). The percentage of REM sleep across the entire night in studies of normal controls ranged from $17.3 \%$ to $24.2 \%$, with a median of $23.1 \%$ on no-dose nights. Relative to the no-dose condition, studies that administered $0.50-0.64 \mathrm{~g} / \mathrm{kg}$ alcohol reported a median $0.7 \%$ decrease in REM sleep as a percentage of sleep time. Studies that administered $0.75-0.80 \mathrm{~g} /$ $\mathrm{kg}$ alcohol reported a median 3.5\% decrease, and studies that administered $0.90-1.2 \mathrm{~g} / \mathrm{kg}$ alcohol reported a median $2.9 \%$ decrease.

The general conclusion is that intoxicating doses of alcohol do not suppress REM sleep; instead, they produce a modest decrease that is most prominent early in the night, with some modest rebound compensation later in the night. Thus, the effects on REM sleep are likely mediated by alcohol itself rather than its metabolites. However, there was a trend in the Landolt et al. study [46] toward a decrease in REM sleep following afternoon alcohol administration ( $17.4 \%$ vs. $19.2 \%$ of total sleep time [TST], despite breath alcohol levels of zero at sleep onset.

\section{Binge/intoxication: effects on NREM sleep}

The major focus of studies that have examined NREM sleep has been on evaluating the effect of alcohol intoxication on light stage 1 drowsiness (N1) as a marker of poor sleep and SWS (N3) as a marker of restorative sleep. Data from studies that reported N1 sleep across the night are presented in Table 4. The median for the no-dose condition in healthy controls is $\sim 7 \mathrm{~min}$. Relative to the no-dose condition, all doses led to median effects of less than a $2 \%$ increase in $\mathrm{N} 1$ across the night. Consistent with the data on WASO, N1 following alcohol intoxication was slightly lower in the first half of the night relative to no-dose nights and slightly higher in the second half of the night (Supplementary Table S3).

The consensus view in the literature is that alcohol increases SWS, particularly early in the night when it typically 
Alcohol use disorder and sleep disturbances: a feed-forward allostatic...

GF Koob and IM Colrain

Table 2. Wakefulness after sleep onset (WASO; \% of total sleep time [TST]) in studies that compared a no-dose (placebo or no alcohol) night to nights in which different doses of alcohol were administered prior to bed and in which data were separated into different portions of the night

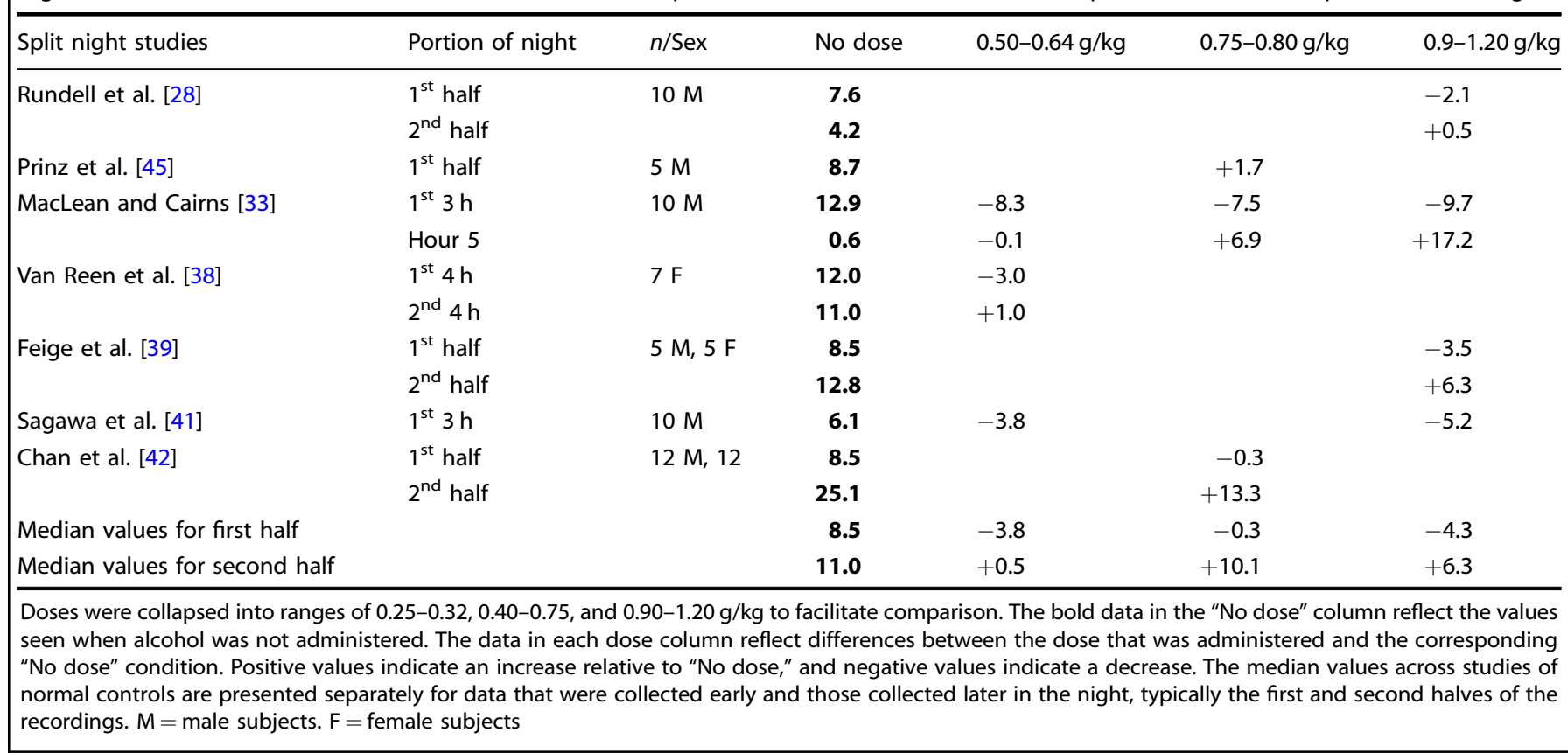

Table 3. REM sleep in studies that compared a no-dose (placebo or no alcohol) night to nights in which different doses of alcohol were administered prior to bed and in which data were separated into different portions of the night

\begin{tabular}{|c|c|c|c|c|c|c|}
\hline Split night studies & Portion of night & $\mathrm{n} / \mathrm{Sex}$ & No dose & $0.50-0.64 \mathrm{~g} / \mathrm{kg}$ & $0.75-0.80 \mathrm{~g} / \mathrm{kg}$ & $0.9-1.2 \mathrm{~g} / \mathrm{kg}$ \\
\hline Rundell et al. [28] & $2^{\text {nd }}$ half & & $30.3 \%$ & & & $+8.6 \%$ \\
\hline \multirow[t]{2}{*}{ MacLean and Cairns [33] } & $1^{\text {st }} 3 \mathrm{~h}$ & $10 \mathrm{M}$ & $11 \%$ & $+0.7 \%$ & $-0.4 \%$ & $-2.0 \%$ \\
\hline & Hour 5 & & $18 \%$ & $+14.5 \%$ & $+14.2 \%$ & $-8.5 \%$ \\
\hline Van Reen et al. [38] & $1^{\text {st }} 4 \mathrm{~h}$ & $7 \mathrm{~F}$ & $12.9 \%$ & $+1.7 \%$ & & \\
\hline \multirow[t]{2}{*}{ Feige et al. [39] } & $1^{\text {st }}$ half & $5 \mathrm{M}, 5 \mathrm{~F}$ & $14.3 \%$ & & & $-2.6 \%$ \\
\hline & $2^{\text {nd }}$ half & & $24.5 \%$ & & & $+0.4 \%$ \\
\hline Sagawa et al. [41] & $1^{\text {st }} 3 \mathrm{~h}$ & $10 \mathrm{M}$ & $8.6 \%$ & $+0.3 \%$ & & $-5.4 \%$ \\
\hline \multirow[t]{2}{*}{ Arnedt et al. [40] (all subjects) } & $1^{\text {st }}$ half & $34 \mathrm{M}, 59 \mathrm{~F}$ & $23.0 \%$ & & & $+0.6 \%$ \\
\hline & $2^{\text {nd }}$ half & & $27.3 \%$ & & & $-4.7 \%$ \\
\hline
\end{tabular}

predominates. As seen in Supplementary Table S4, the studies showed a range of SWS in the no-dose condition between $12 \%$ and $30.5 \%$ of TST across the whole night. When collapsing the data across the whole night of sleep, a modest dose-related increase in SWS was observed. As shown in Table 5, however, this effect was highly variable across the night. There were increases in SWS following intoxication relative to the no-dose condition in the first half of the night, followed by decreases in the second half of the night when WASO and N1 increased.

The general conclusion for NREM sleep is that intoxicating doses of alcohol lead to increases in SWS early in the night but a deterioration of sleep quality (i.e., an increase in $\mathrm{N} 1$ and decrease in SWS later in the night). 


\begin{tabular}{|c|c|c|c|c|c|}
\hline Studies of controls & $n /$ Sex & No dose & $0.50-0.64 \mathrm{~g} / \mathrm{kg}$ & $0.75-0.80 \mathrm{~g} / \mathrm{kg}$ & $0.9-1.20 \mathrm{~g} / \mathrm{kg}$ \\
\hline Williams et al. [35] & $11 \mathrm{~F}$ & $3.9 \%$ & $+2.4 \%$ & $+5.3 \%$ & \\
\hline Roehrs et al. [36] (8 $\mathrm{h}$ tib previous night) & $5 \mathrm{M}$ & $11.9 \%$ & & $-1.9 \%$ & \\
\hline Roehrs et al. [37] (controls) & $9 \mathrm{M}+\mathrm{F}$ & $12.3 \%$ & $-0.5 \%$ & & \\
\hline Feige et al. [39] (0.10\% blood alcohol level condition) & $5 \mathrm{M}, 5 \mathrm{~F}$ & $5.2 \%$ & & & $+1.2 \%$ \\
\hline Arnedt et al. [40] (male subjects) & 34 M. $59 \mathrm{~F}$ & $4.5 \%$ & & & $-0.4 \%$ \\
\hline Arnedt et al. [40] (female subjects) & & $3.5 \%$ & & & $+0.5 \%$ \\
\hline Median values for studies of controls & & $6.9 \%$ & $+1.0 \%$ & $+1.7 \%$ & $+0.5 \%$ \\
\hline \multicolumn{6}{|l|}{ Studies of non-normal sleep } \\
\hline
\end{tabular}

Table 5. Slow-wave sleep in studies that compared a no-dose (placebo or no alcohol) night to nights in which different doses of alcohol were administered prior to bed and in which data were separated into different portions of the night

\begin{tabular}{|c|c|c|c|c|c|c|}
\hline Split night studies & Portion of night & $n /$ Sex & No dose & $0.50-0.64 \mathrm{~g} / \mathrm{kg}$ & $0.75-0.80 \mathrm{~g} / \mathrm{kg}$ & $0.9-1.20 \mathrm{~g} / \mathrm{kg}$ \\
\hline & $2^{\text {nd }}$ half & & $6.9 \%$ & & & $-4.6 \%$ \\
\hline \multirow[t]{2}{*}{ MacLean and Cairns [33] } & $1^{\text {st }} 3 \mathrm{~h}$ & $10 \mathrm{M}$ & $39.1 \%$ & $+0 \%$ & $+4 \%$ & $+7 \%^{+}$ \\
\hline & Hour 5 & & $13.8 \%$ & $-6 \%$ & $-9 \%$ & $-9 \%$ \\
\hline Van Reen et al. [38] & $1^{\text {st }} 4 \mathrm{~h}$ & $7 \mathrm{~F}$ & $35.0 \%$ & $+0.4 \%$ & & \\
\hline \multirow[t]{2}{*}{ Williams et al. [35] } & Hours 1-3 & $11 \mathrm{~F}$ & $24.8 \%$ & $+4 \%$ & $+6 \%$ & \\
\hline & Hours 4-6 & & $7.0 \%$ & $-3 \%$ & $-6 \%$ & \\
\hline \multirow[t]{2}{*}{ Feige et al. [39] } & $1^{\text {st }}$ half & $5 \mathrm{M}, 5 \mathrm{~F}$ & $20.0 \%$ & & & $+11.0 \%$ \\
\hline & $2^{\text {nd }}$ half & & $4.1 \%$ & +0.0 & & $-2.1 \%$ \\
\hline Sagawa et al. [41] & $1^{\text {st }} 3 \mathrm{~h}$ & $10 \mathrm{M}$ & $27.0 \%$ & $+2.1 \%$ & & $+5.5 \%$ \\
\hline Median values for first half & & & $29.9 \%$ & $+1.3 \%$ & $+5.2 \%$ & $+5.5 \%$ \\
\hline Median values for second half & & & $9.6 \%$ & $-3.5 \%$ & $-5.6 \%$ & $-3.4 \%$ \\
\hline
\end{tabular}

Binge/intoxication: effects on EEG

The impact of alcohol on the sleep architecture measures that are reported above are based on visual analysis of polysomnogram (PSG) recordings that are based on a consensus scoring system of pen chart recorder data that were adopted in 1968 [11] that was itself based on work from the 1930s [47-49]. Digital recordings have now replaced analog ink-on-paper records, and digital signal processing of the EEG can reveal subtle effects of alcohol that may vary according to brain region and that are not evident from the manual scoring of PSGs.

Few investigations have examined the acute effects of alcohol on EEG power spectra, the results of which are summarized in Table 6. The interpretation of the data is complicated by a number of factors. Rundell et al. [28] reported data only from a single 
Alcohol use disorder and sleep disturbances: a feed-forward allostatic...

GF Koob and IM Colrain

Table 6. Studies that used spectral analysis of sleep EEG following alcohol administration prior to bedtime

\begin{tabular}{|c|c|c|c|c|c|c|c|c|}
\hline Studies of controls & $n /$ Sex & Portion of night & Dose & Delta & Theta & Sigma & Alpha & Beta \\
\hline Rundell et al. [28] & & $1^{\text {st }}$ half & & & Decrease & & Increase ${ }^{a}$ & Decrease $^{b}$ \\
\hline Dijk et al. [50] & & Whole night & & & Decrease $^{\mathrm{e}}$ & & & \\
\hline Landolt et al. [46] & $10 \mathrm{M}$ & Whole night ${ }^{f}$ & $0.55 \mathrm{~g} / \mathrm{kg}$ & Increase ${ }^{d}$ & & & & \\
\hline Van Reen et al. [38] & $7 \mathrm{~F}$ & Whole night & $0.49 \mathrm{~g} / \mathrm{kg}$ & & Increase ${ }^{c, d}$ & & Increase ${ }^{d}$ & Increase ${ }^{\mathrm{e}}$ \\
\hline \multirow[t]{4}{*}{ Chan et al. [51] } & $12 \mathrm{M}, 12 \mathrm{~F}$ & Cycle 1 & $\sim 0.8 \mathrm{~g} / \mathrm{kg}$ & Increase ${ }^{d}$ & & & Increase ${ }^{d}$ & \\
\hline & & Cycle 2 & & & & & Increase ${ }^{d}$ & \\
\hline & & Cycle 3 & & & & & Increase ${ }^{d}$ & \\
\hline & & Cycle 4 & & Decrease $^{d}$ & & & Decrease $^{d}$ & \\
\hline
\end{tabular}

Commonly used frequency bands are marked as significantly increased or decreased relative to a no-dose condition

ancrease was in the 1 st derivative

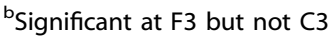

${ }^{\mathrm{c}} 4 \mathrm{~Hz}$ only

dIn NREM

e In REM

${ }^{\mathrm{f}}$ Alcohol administered $5 \mathrm{~h}$ prior to bedtime with blood alcohol level of 0.0 at lights out. $\mathrm{M}=$ male subjects. $\mathrm{F}=$ female subjects

central EEG site for delta, theta, and alpha activity and from a frontal site for higher frequencies. Dijk et al. [50] reported data only from a single central electrode. Landolt et al. [46] reported data from several scalp regions and showed frontal and central EEG effects but only in the first sleep cycle and in response to alcohol that was administered $6 \mathrm{~h}$ prior to sleep.

The frontal predominance was supported by Van Reen et al. [38] in a study of young women who ingested alcohol in the hour prior to sleep, with an increase in NREM alpha that lasted all night, but the increase in NREM delta was specific to the first sleep cycle. Chan et al. [51] confirmed the alpha and delta EEG effects, in which both frequencies had larger effects over the frontal scalp and showed a decrease in the magnitude of both across sleep cycles.

Similar to SWS, delta power increases early in the night and can decrease later in the night following intoxication. Thus, for the low-frequency EEG that is dominant in SWS, the frequency analysis is consistent with visual scoring. Alpha activity that is typically seen in relaxed wakefulness does not track WASO. Alpha increases in the first half of the night. Chan et al. [51] reported that it can occur in the context of background delta activity as so-called alpha-delta sleep. This pattern, which has been seen in patients with pain or who awake unrefreshed [52], could indicate that despite increases in delta activity and SWS, sleep may be less restorative following alcohol intoxication.

Binge/intoxication: repeated administration over several nights If a relationship exists between the development of AUD and sleep issues that are associated with intoxication, then such a relationship emerges over the course of multiple days of drinking and may not be reflected by data from a single-night study. Unfortunately, only very few studies have assessed effects of the repeated administration of intoxicating doses of alcohol on sleep over several nights. In studies that investigated SOL over multiple nights of alcohol administration [28, 39], SOL was reduced across all three drinking nights [28, 39], with no clear evidence of adaptation of the effect over the three consecutive nights. The effects of a decrease in WASO in the first half of the night showed little change over three nights in two studies $[28,39]$ but showed evidence of increases over nine nights in another study [45]. WASO in the second half of the night was elevated relative to baseline across all drinking nights when all drinking nights were assessed $[28,39]$ (not reported in [45]).

For REM sleep, neither Rundell et al. [28] nor Feige et al. [39] reported systematic effects over the three nights for either the first or the second half of the night (Fig. 2). Prinz et al. [45] reported a decrease on night 1 that was still present on night 9 for the first half of the night but did not present data for the second half. For SWS, both Rundell et al. [28] and Feige et al. [39] reported initial increases for the first half of the night that appeared to habituate over the three nights of the study. For the second half of the night, both studies reported decreases in SWS that stayed flat over the three nights (Fig. 2). Prinz et al. [45] reported an initial increase that was not seen on night 9.

Drawing definitive conclusions from these three studies is difficult. In terms of WASO, however, drinking over multiple days does not appear to lead to habituation of the effects that are seen in studies of a single night of sleep following intoxication.

Binge/intoxication: sleep effects of alcohol administration in AUD Experimental studies of the impact of alcohol intoxication on sleep in healthy controls are useful for providing insights into the ways in which intoxication might impact sleep and the ways in which the effects on sleep might contribute to the development of AUD. However, a clearer understanding of this relationship might be produced by studying the impact of alcohol intoxication on sleep in AUD patients. Such studies are not currently possible because of ethical and treatment guidelines for AUD. In the early 1970s, however, a few studies were conducted that are useful for review. These studies were conducted not long after the development of consensus standards for sleep scoring [11] with equipment that had recording and analysis limitations relative to equipment that is available to investigators today. Thus, some caution needs to be exercised when looking at absolute values of the data, but relative changes within datasets can still be informative.

Johnson et al. [53] studied 14 alcoholics for two nights following days in which they consumed bourbon every $2 \mathrm{~h}$ starting at 0800 hours. All of the subjects had a blood alcohol level of at least $0.11 \mathrm{~g} \%$ at 8:00 PM. SOL did not change substantially in recovery vs. drinking. WASO and N1 (20\% and $22 \%$, respectively) appeared to be slightly higher when drinking compared with the first $(18 \%$ and $15 \%)$ and last (17\% and $18 \%)$ recovery nights. SWS decreased from a very low $3.2-2.1 \%$ on the first recovery night but 
Repeated Dose Effects on REM\%

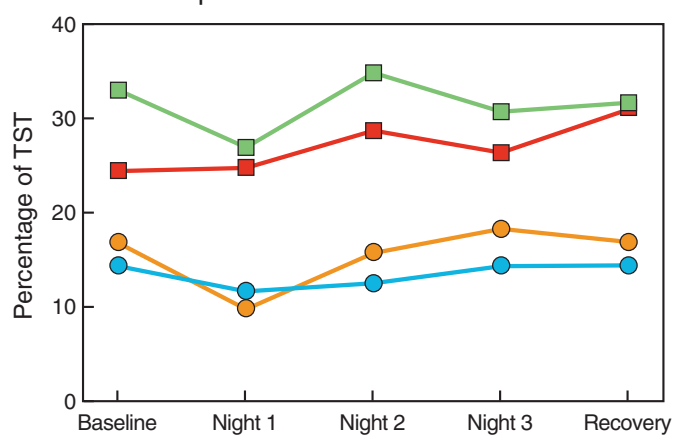

Repeated Dose Effects on SWS\%

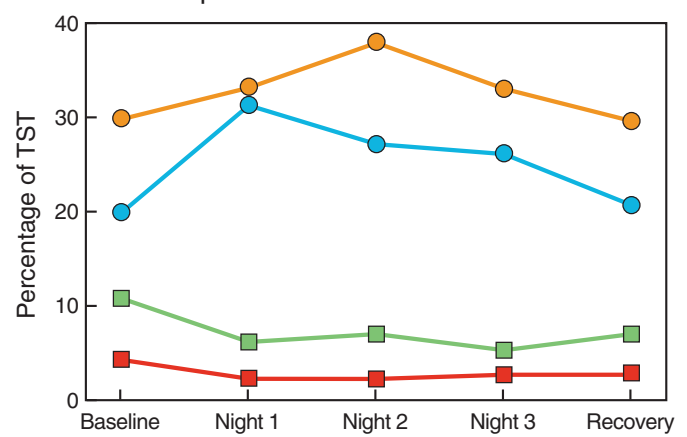

Rundell et al. (1972) 1st half
$\square$ Rundell et al. (1972) 2nd half
Feige et al. (2006) (0.10\% BAC condition) 1st half
$\square$ Feige et al. (2006) (0.10\% BAC condition) 2nd half

Fig. 2 Data from Rundell et al. [28] and Feige et al. [39]. REM\% (left panel) and SWS\% (right panel) in healthy controls sober at baseline, from three nights of drinking and the first recovery night. Data are presented separately for the first and second halves of the night

progressively increased to $5.8 \%$ by the last recovery night. REM sleep increased from $18 \%$ when drinking to $21 \%$ on the first recovery night and showed no further changes (Supplementary Table S5).

Allen et al. [54] reported data from six male alcoholics, five of whom were studied for 3-7 days while drinking $30 \mathrm{ml}$ of $95 \%$ pure alcohol in juice every $2 \mathrm{~h}$ from 0800 to 2200 hours. All of the subjects were then denied alcohol and studied for the first 7 days of abstinence. Data were then collected after a further week of abstinence. The sixth subject was withdrawn from alcohol on admission and studied for 1 week of withdrawal and then after a further week of abstinence. For the present review, data are summarized by averaging all of the drinking nights and comparing them to nights off alcohol for the first five subjects. Because of technical issues, filtering of the data for several subjects did not permit the recording of SWS. Subjects were admitted to the study via emergency room admission and were given their first experimental dose of alcohol within $12 \mathrm{~h}$ of their last drink. They were thus studied after a prolonged period of intoxication. REM sleep was not completely suppressed by drinking in this context. REM sleep also did not rebound upon withdrawal. Instead, it presented gradual recovery that began at around 4 days of abstinence. Somewhat paradoxically, SOL was very fast on the first withdrawal night but then increased dramatically, only normalizing after 1 week of abstinence. WASO and N1 sleep did not appear to be affected much by drinking or withdrawal (Supplementary Table S6).

Gross et al. [55] studied four alcoholic men after 6 days of inpatient treated abstinence. The subjects were studied under two conditions in a counterbalanced design. They spent 15 days in a "wet" condition in which they had a baseline of 3 days with no alcohol, followed by 1 day of alcohol adaptation, 4 days of "alcoholization," 3 days of withdrawal, and 4 days of "recovery." The alcoholization days consisted of heavy drinking with an average consumption of $3.1 \mathrm{~g} / \mathrm{kg}$. The dry condition consisted of the number of nights but with no alcohol adaptation or heavy drinking. Data from the wet and dry conditions were then compared across the same nights in the sequence. SOL increased with alcohol and during initial withdrawal relative to baseline and recovery. SWS increased with alcohol but was lower than baseline during initial withdrawal and recovery. REM sleep was suppressed when drinking but did not show a rebound during withdrawal or recovery relative to baseline (Supplementary Fig. S1).

Lester et al. [56] studied 17 male alcoholics for two baseline nights after at least 3 weeks of sobriety and for two nights (alcohol) following days in which they drank from 1300 until 2100 hours with bedtime blood alcohol levels of $0.15 \mathrm{~g} \%$ and then for two nights following withdrawal (recovery) and a subsequent night after a further week of abstinence. Data were reported separately for the first and second halves of the night. WASO and $\mathrm{N} 1$ decreased with alcohol and then returned to baseline. \%REM in the first half of the night decreased from $18.6 \%$ at baseline to $12.1 \%$ while drinking and returned to $19.3 \%$ in withdrawal. In the second half of the night, it decreased from $33.9 \%$ at baseline to $12.1 \%$ while drinking and partially recovered to $19.3 \%$ during withdrawal. Slow-wave sleep showed a dramatic increase while drinking and recovery to slightly above baseline for the first half of the night and substantially above baseline for the second half of the night when measured during withdrawal (Supplementary Table S7).

Wagman and Allen [57] studied six male alcoholics who had been sober for at least 7 days. Data were collected at baseline and then during 5 days of receiving 18 ounces of $95 \%$ proof alcohol, followed by 5 days of 26 ounces and then at least 1 day of 32 ounces. Data were then collected after 1 week of abstinence. Only SWS data were reported. The baseline value of $~ 3 \%$ SWS increased to $\sim 10 \%$ at 18 ounces and then to around $13 \%$ at 26 ounces and $16 \%$ at 32 ounces, dropping back to $5 \%$ after 1 week of no alcohol.

Gross and Hastey [58] studied 10 young male alcoholics for a baseline period of $\sim 3.5$ weeks postadmission. Following the baseline, they received alcohol $(1.6 \mathrm{~g} / \mathrm{kg}$ on day 1 and $3.2 \mathrm{~g} / \mathrm{kg}$ on subsequent days) for either 5 or 7 days. They were then denied alcohol and studied for 7 days of withdrawal. They were somewhat arbitrarily divided into two groups based on the percentage of SWS on the baseline nights. The "low" group had SWS values between 14 and 29\%, and the "high" group had SWS values between 32 and $44 \%$. In both groups, \%SWS was elevated while drinking relative to baseline and dropped to below baseline levels upon withdrawal from alcohol, with the appearance of a gradual recovery over days of abstinence (Supplementary Fig. S2).

Although the focus of the study was on SWS, the authors reported REM data during withdrawal relative to the values that were seen at baseline and the minimum value that was seen while drinking. REM sleep dropped to zero in both groups at some point over the drinking nights and recovered to baseline (or slightly less than baseline) on the first withdrawal night. For the low SWS group, REM sleep exceeded baseline on the second withdrawal night (Supplementary Fig. S3).

The general trends of drinking and withdrawal effects on sleep variables are summarized in Table 7 . Although some variability is 
Table 7. Summary of trends from studies in which alcohol was administered to AUD patients and then withdrawn

\begin{tabular}{|c|c|c|c|c|c|c|c|c|c|c|}
\hline & \multicolumn{2}{|l|}{ SOL } & \multicolumn{2}{|l|}{ WASO } & \multicolumn{2}{|l|}{ N1 } & \multicolumn{2}{|l|}{ SWS } & \multicolumn{2}{|l|}{ REM } \\
\hline Johnson et al. [53] & & $\Delta$ & & $\nabla$ & & $\nabla$ & & $\nabla \mathbf{\Delta}$ & & $\Delta$ \\
\hline Gross et al. [55] & & $\leftarrow \rightarrow$ & & & & & $\boldsymbol{\Delta}$ & $\nabla$ & $\nabla$ & $\leftarrow$ \\
\hline Lester et al. [56] & & & $\nabla$ & $\Delta$ & $\nabla$ & $\Delta$ & $\Delta$ & $\nabla$ & $\nabla$ & $\Delta$ \\
\hline
\end{tabular}

Closed triangles indicate strong effects, and open triangles indicate weaker effects in the direction indicated. Drinking effects are indicated relative to baseline. Withdrawal effects are indicated relative to drinking. $\leftarrow \rightarrow$, no effect observed. Multiple triangles reflect the magnitude and direction of effects that differed in different stages of withdrawal (e.g., $\boldsymbol{\nabla} \Delta \boldsymbol{\nabla}$ indicates a strong decrease followed by a weaker increase followed by a strong decrease)
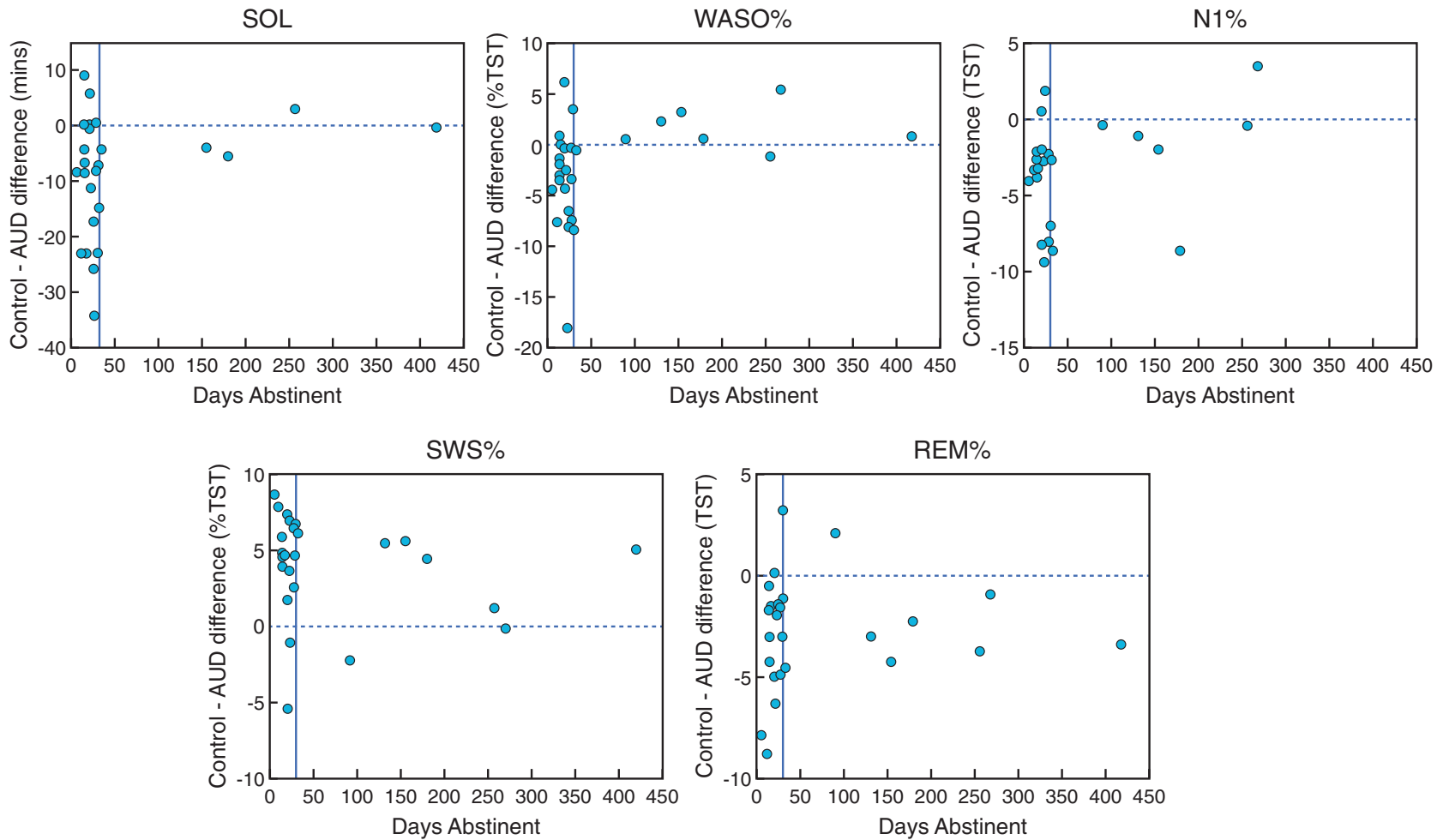

Fig. 3 Difference scores between control and AUD values for sleep onset latency (SOL) and the percentage of total sleep time (TST) spent awake (WASO\%), N1 sleep (N1\%), slow-wave sleep (SWS\%), and REM sleep (REM\%). The dashed horizontal line marks the point of no difference between controls and AUD. The solid vertical line marks the 30 boundary between short- and long-term abstinence. Data are presented as a function of the length of time abstinent

observed, as with the data above in normal controls, administering alcohol to AUD patients leads to an increase in SWS that then subsequently decreases upon withdrawal. Likewise, drinking decreases (but does not entirely suppress) REM sleep, with some variability in recovery upon withdrawal. The binge/intoxication effects on sleep are summarized in Fig. 1.

\section{SLEEP IN RECENTLY SOBER AUD: WITHDRAWAL/NEGATIVE AFFECT DOMAIN}

Withdrawal/negative affect: effects on sleep

In AUD patients, their ubiquitous, chronic, and long-lasting sleep issues are a cause of negative affect. Some of the reported high comorbidity of insomnia and alcoholism [59] may be attributable to poor sleep habits and irregular sleep-wake schedules that are an inevitable consequence of drinking. Changes in brain structure, function, and neurochemistry [5] may also play a role. Certainly, the incidence of insomnia in AUD has been reported to be as high as $91 \%$ [60].

For the purposes of this review, recent abstinence is somewhat arbitrarily considered to be within the first 30 days, the typical duration of short inpatient treatment programs. Several studies are available in which AUD patients at different stages of abstinence (7-30 days) are compared with control subjects (typically non-AUD social drinkers) [56, 61-72]. Data that are presented in this section thus reflect differences between AUD and control data relative to the time of abstinence in the AUD groups. 
SOL for abstinent AUD in these studies ranged from $35.1 \mathrm{~min}$ longer to $8.3 \mathrm{~min}$ shorter than controls and was an average of $10.6 \pm 12.2$ min longer [56, 61-72]. WASO \% for abstinent AUD ranged from $5.7 \%$ less to $18.6 \%$ more than in controls and was an average of $4.1 \% \pm 5.1 \%$ more. N1\% in abstinent AUD ranged from $1.6 \%$ less to $9.7 \%$ more than in controls and was an average of $3.7 \% \pm 2.9 \%$ more. Short-term abstinent AUD individuals take longer to get to sleep and have more time awake or in N1 drowsiness (Fig. 3). In the same studies, SWS\% in abstinent AUD ranged from $5.6 \%$ higher to $8.6 \%$ lower than in controls with a median of $4.5 \%$ lower (and 15 of the 17 datasets showed AUD lower than controls). Finally, REM sleep in abstinent AUD ranged from no difference to $9 \%$ more than in controls and with a median of $3.1 \%$ more. Short-term abstinent AUD subjects took longer to get to sleep and had more time awake or more time in N1 drowsiness. Figure 3 shows the values for each of these variables as a function of the average number of days abstinent in each of the studies from which they were drawn. What is apparent is that for all of these measures, data are highly variable, and there is no trend toward recovery within 30 days.

\section{Withdrawal/negative affect: effects on EEG}

The spectral analysis of sleep EEG data was conducted within 30 days of withdrawal in fewer studies. Consistent with reports of a reduction of SWS, Irwin et al. [66] reported significantly lower NREM delta power $(0.75-4 \mathrm{~Hz})$ across the entire night in alcoholics who were abstinent for $\sim 30$ days relative to controls, particularly in the first NREM period. Irwin et al. [67] studied the impact of sleep deprivation on SWS and delta EEG power in European American and African American subjects. Both AUD groups (abstinent before testing for on average of 23 days) showed a decrease in delta power relative to controls in the baseline condition, an effect that was more pronounced in the African American AUD group. Importantly, neither AUD group showed the typical increase in delta power during the recovery night following sleep deprivation (which was observed in their respective control subjects). They also saw a trend toward higher beta activity in alcoholics across the entire night at baseline that became a significant difference during a recovery night following a night of partial sleep deprivation.

Feige et al. [70] studied AUD subjects in the third week of an inpatient treatment program. Subjects with AUD were divided into two groups based on relapse status at 3 months posttreatment. The abstaining group had lower delta power compared with the relapsing group and controls in N2 sleep. They also reported higher beta activity during REM sleep in the relapsing group compared with the abstaining group and controls. Both effects, although significant, were small and inconsistent across two nights of measurement.

Singh et al. [72] studied AUD subjects after 2-3 weeks of treatment and a further week of washout from lorazepam. EEG analysis was conducted during early NREM sleep (N1+N2), SWS, and REM sleep at left and right frontal, temporal, parietal, and occipital sites. Delta power was lower in patients during N1+N2 and SWS at the left and right temporal sites and right parietal and occipital sites. Alpha power increased in patients during $\mathrm{N} 1+\mathrm{N} 2$ at the left occipital site, where $30-50 \mathrm{~Hz}$ activity was also elevated during SWS. REM sleep displayed higher beta activity in patients bilaterally at all sites and higher $30-50 \mathrm{~Hz}$ activity at right parietal and occipital sites.

Another approach to measuring the brain's ability to generate delta frequency responses is via auditory evoked responses. A proportion of stimuli will elicit a single delta waveform response, known as a K-complex [73]. K-complexes behave much like SWS and delta power, in which their amplitude decreases with aging [74], and differences between subjects are at least partially attributable to differences in cortical gray matter volume [75]. We recently conducted a study in which 16 AUD subjects were initially studied at an average of 17 days of abstinence and then 1 month and 3 months after the first assessment [76]. Control subjects were also studied at each time point. At the initial assessment, both the proportion of trials in which K-complexes were elicited (a measure of the facility of the brain to generate delta activity) and the amplitude of the averaged K-complex response significantly decreased in AUD. The withdrawal/negative affect effects on sleep are summarized in Fig. 1.

\section{LONG-TERM SLEEP EFFECTS IN ABSTINENT AUD: PREOCCUPATION/ANTICIPATION DOMAIN}

Preoccupation/anticipation: effects on sleep

A few studies investigated sleep in AUD subjects who were abstinent for $>30$ days $[61,65,77-80]$. These data are also shown in Fig. 3.

The ideal design for studying the effects of long-term abstinence includes longitudinal assessments that are conducted within the same subjects at increasing lengths of time sober. Rundell et al. [61] studied 20 AUD subjects near the beginning and again near the end of a 13-week treatment program and compared them to 20 age-matched controls. SOL, N1\%, and REM sleep were elevated, and SWS decreased at both time points compared with controls. Some evidence of recovery in SWS and REM sleep was observed at the second time point. A subset of six subjects was studied 6 months after release from the hospital. For these subjects, SWS showed further recovery at 6 months but was still lower than control values. SOL and REM sleep exhibited no further recovery from 12 weeks to 6 months.

Williams and Rundell [77] studied 46 AUD subjects in two sessions: the first at 35 days sober and the second at 92 days sober. SOL was elevated relative to controls at 35 days, with some partial recovery at 92 days. N1\% remained elevated at both time points. SWS\% was lower and REM\% was higher in AUD subjects than in controls at 35 days. Both variables showed only partial recovery to control values at 92 days. Twenty-four subjects returned for a third session 9 months after entering the program. Of these, 14 had resumed drinking, and 10 remained abstinent. These data are difficult to quantify because the earlier time points were not separated into these groups. At 9 months, however, the abstaining AUD subjects had reductions of \% WASO and N1\% and more SWS than those who were released. REM sleep in relapsed AUD subjects was lower than in control subjects.

Drummond et al. [65] studied 29 AUD subjects at 16 days sober and again at 19 weeks sober and a group of age-matched controls. SOL was higher in AUD subjects than in controls at both time points. WASO remained elevated at 16 days but decreased at 19 weeks. REM sleep remained elevated at both time points, and SWS was suppressed at both time points. Nine sober AUD subjects returned for further evaluation at 14 months. These subjects showed no further improvements in sleep values compared with subjects at 19 weeks.

When these data are combined with those of others with a single time point [78-80], the following patterns emerge. SOL for abstinent AUD in these studies ranged from $15.8 \mathrm{~min}$ longer to 2.4 min shorter than controls and was an average of $5.44 \pm 5.72$ min longer. WASO $\%$ for abstinent AUD subjects ranged from $5.1 \%$ less to $8.7 \%$ more in controls and was, on average, recovered to control values $(0.27 \% \pm 5.1 \%$ less). $\mathrm{N} 1 \%$ in abstinent AUD subjects ranged from $3.3 \%$ less to $9.0 \%$ more than in controls and was an average of $3.0 \% \pm 4.1 \%$ more. SWS\% in abstinent AUD ranged from $2.4 \%$ higher to $6.5 \%$ lower than in controls and was an average of $3.7 \% \pm 3.1 \%$ lower. Finally, REM sleep in abstinent AUD subjects ranged from $3.0 \%$ less to $4.7 \%$ more than in controls and was an average of $1.9 \% \pm 2.7 \%$ more. Figure 3 shows the values for each of these variables as a function of the average number of days abstinent in each of the studies from which they were drawn. 
Preoccupation/anticipation: effects on EEG

EEG spectral analysis was conducted in 14 AUD subjects and matched controls by Irwin et al. [79] at $31 \pm 28$ days sober for data that were collected in the first sleep cycle. During NREM and REM sleep, delta and theta activity was significantly less in AUD subjects. Beta activity was significantly less in NREM sleep, with a trend toward a decrease in REM sleep. Colrain et al. [80] reported spectral analysis data from multiple EEG sites in male AUD subjects who had been sober for an average of $156.6 \pm 161.8$ days and female AUD subjects who had been sober for an average of $258 \pm 217.1$ days. Relative to controls, alcoholics had significantly lower NREM sleep across the whole night and in the first NREM period in the slow $(<1 \mathrm{~Hz})$ band and in each of the 1 to $<2,2$ to $<3$, and 3 to $<4 \mathrm{~Hz}$ delta EEG bands. The slower end of theta activity (up to $6 \mathrm{~Hz}$ ) displayed a similar pattern to delta frequencies. The effects were more prominent in frontal than posterior scalp derivations in alcoholic men and women. The delta effects were not seen in REM sleep. They did not report any differences in alpha or beta activity during sleep.

Two studies evaluated sleep evoked delta responses in AUD. Nicholas et al. [81] studied seven AUD subjects who had been abstinent for 70-726 days who met the DSM-IV criteria [82] for alcohol dependence and eight normal control men. Subjects with AUD were significantly less likely to generate a K-complex in response to a tone and had significantly smaller amplitude responses. In a larger study, Colrain et al. [83] studied 42 abstinent long-term alcoholics (27 men) and 42 controls (19 men). These subjects were the same as those reported in Colrain et al. [80] above. Subjects with AUD were significantly less likely to produce K-complexes than controls. Frontal (but not posterior) amplitude of the average response was significantly smaller in AUD subjects. A subset of 15 of the AUD subjects was followed for a further 12 months and had significantly higher amplitudes of the average K-complex response [84]. Finally, in the Willoughby et al. study [76] above, no further recovery was observed in either the proportion of trials in which K-complexes were elicited or the amplitude of the average K-complex response at 3 months sober over that seen at 1 month sober. The preoccupation/anticipation effects on sleep are summarized in Fig. 1.

\section{SEX DIFFERENCES IN SLEEP INTERACTIONS WITH ALCOHOL AND AUD}

Few studies have investigated the influence of sex differences on the ways in which drinking to intoxication, withdrawal, and protracted abstinence affect sleep. Sex differences have been reported in drinking patterns and pharmacokinetics of alcohol. Women tend to have less body water and more body fat than men and thus tend to have higher blood alcohol levels than men after consuming the same amount of alcohol because of alcohol's hydrophilic properties [85]. Historically, AUD has been around fivetimes more prevalent among men than among women, but the gender gap is decreasing with regard to both alcohol consumption and AUD, at least in the United States $[86,87]$, including binge drinking [88]. Women are more vulnerable to the development of alcohol-related diseases, such as liver cirrhosis [89], cardiomyopathy [90], and cancer [91]. Alcohol-dependent women have worse quality-of-life scores than alcohol-dependent men [92]. However, although the risk of developing insomnia is 1.41-times higher in women [93], no sex differences were found in the frequency of insomnia in men and women who underwent treatment for alcohol dependence [94].

As shown in Table 1-6, most studies of the effects of acute alcohol on sleep either did not investigate female subjects or had sample sizes that were too small to evaluate possible sex differences in the data. The two studies with sufficient numbers of men and women reported different results. Arnedt et al. [40] found that drinking to intoxication resulted in more sleep disturbances (i.e., decrease in sleep efficiency and increase in wakefulness) but a similar impact on sleep architecture (i.e., \%SWS and \%REM sleep) in healthy women compared with men. However, Chan et al. [42] found no sex differences in the effects of alcohol on sleep in older adolescents.

Most studies of early withdrawal and extended abstinence have also either used only male subjects or did not evaluate sex differences. Colrain et al. [80] reported that women had better sleep efficiency and more delta activity during NREM sleep than men, regardless of diagnosis, and that men with AUD appeared to present a more pronounced reduction of delta activity during NREM sleep than women with AUD. Furthermore, estimated lifetime alcohol consumption predicted the percentage of SWS in men with AUD but not in women with AUD. Estimated lifetime alcohol consumption was higher in alcoholic men than in alcoholic women, and the women had longer periods of sobriety prior to testing.

With the growing prevalence of AUD in women, studies need to include larger samples of men and women with AUD to further evaluate possible sex differences in the effects of drinking to intoxication, alcohol withdrawal, and protracted abstinence on sleep.

\section{POSSIBLE NEUROCHEMICAL MECHANISMS OF THE EFFECTS OF ALCOHOL ON SLEEP, PARALLELED BY NEUROCHEMICAL CHANGES ACROSS THE ADDICTION CYCLE}

Sleep is associated with a complex set of interactions between two major neurotransmitter systems: acetylcholine and norepinephrine (for review, see $[95,96]$ ). For example, NREM sleep is a period during which cholinergic and noradrenergic brainstem arousal mechanisms are dramatically reduced. The transitions between NREM and REM sleep involve a complex interaction between REM-on and REM-off neuronal groups in the brainstem. REM-on groups largely consist of cholinergic cells in the lateral dorsal tegmentum (LDT) and pedunculopontine tegmental nucleus (PPT). REM-off cells involve serotonergic neurons in the dorsal raphe nucleus and noradrenergic locus coeruleus. A set of reciprocal interactions between the two groups of neurons, whereby REM-on neurons are influenced by a self-excitatory loop but also have an excitatory link to REM-off neurons, has long been hypothesized, a model that was originally developed by McCarley and Hobson [97]. REM-off cells dominate once a threshold of activation is reached, and they have an inhibitory action on REMon cells but are also part of a self-inhibitory feedback loop that progressively decreases their activity. Eventually, REM-off cell activity drops below a threshold, and REM-on cells regain dominance.

Alcohol interacts with both cholinergic and noradrenergic brainstem systems but possibly via some of the same neurotransmitter circuitry that is involved in mediating the incentive salience/pathological habit, reward deficit/stress surfeit, and executive function domains that are described above. For the purposes of this review, we explore the effects of alcohol on the neurotransmitter systems that are considered key to the addiction cycle outlined above.

Neurochemistry of sleep relevant to the binge/intoxication stage $G A B A$. The acute effects of alcohol on decreasing sleep latency, increasing SWS, and increasing EEG delta power can possibly be explained by the GABA receptor agonist properties of alcohol. Alcohol exposure leads to the presynaptic release of GABA throughout the CNS. Within the thalamus, the hyperpolarizing effect of GABA causes the opening of low-threshold $\mathrm{Ca}^{2+}$ ion channels and a pattern of synchronized burst firing that manifests as sleep spindles on the sleep EEG. The further release of GABA causes greater levels of hyperpolarization and the production of 
delta EEG waveforms [98]. The subsequent withdrawal of tonic input to the reticular nucleus allows the release of GABA and inhibition of thalamo-cortical circuits [99]. These effects, plus the alcohol-induced release of GABA in the brainstem [100], may also play a role in alcohol's suppression of REM sleep in the context of high doses of alcohol.

The increase in delta activity that is produced by acute alcohol early in the night is also consistent with alcohol's GABA receptor agonist properties. EEG delta activity is partially mediated by the GABA-induced hyperpolarization of cortical and thalamo-cortical neurons [99]. There is evidence that acute alcohol modulates metabotropic glutamate receptor (mGluR)-mediated slow currents [2] that are thought to underlie the slow oscillation of thalamocortical cell activity that underlies delta generation [101]. Further hyperpolarization can lead to the cessation of spindle activity and the development of delta activity [102]. Sleep spindles (associated with sigma frequency power) are produced when thalamo-cortical cells become hyperpolarized, resulting in low-threshold spikes and the generation of spindle frequency activity in thalamic reticular cells [102]. Alcohol consumption causes a decrease in sigma power [50], but benzodiazepines cause spindle and sigma facilitation [103]. These findings are consistent with older data that show inverse effects of benzodiazepines on sigma and delta activity [104]. Recent work identified an important role for GABAergic interneurons that act to facilitate the REM-off process [105]. Alcohol may influence this REM-off process through its effects on GABA, leading to the suppression of REM sleep in the short-term.

Dopamine. Historically multiple neurotransmitter systems-norepinephrine, serotonin, acetylcholine, histamine, adenosine, hypocretin/orexin, and dopamine-have been studied in the context of behavioral arousal. Neurons in the locus coeruleus, dorsal raphe nucleus, and tuberomammillary nucleus fire fastest during wakefulness, slow during non-REM sleep, and nearly stop firing completely during REM sleep. Cholinergic neuron firing contributes to arousal and REM sleep. However, these neurotransmitter systems are only indirectly related to the acute reinforcing effects of alcohol. In contrast, the mesocorticolimbic dopamine system plays a key role in incentive salience and begins the process of pathological habits [106]. However, its role in sleep-wake regulation has been scarcely studied. The dopamine neuron firing rate varies little between sleep and wake states [107, 108], although lesions of dopamine cell groups in the ventral tegmentum that project to the forebrain significantly reduced behavioral arousal in rats [109]. Parkinson's disease patients, who exhibit pronounced dopamine lesions, experience severe sleep disorders $[110,111]$. Dopamine $D_{1}$ and $D_{2}$ receptors have been clearly implicated in the induction of hyperarousal [112]. The existence of sleep state-dependent dopaminergic neurons has been reported in the ventral periaqueductal gray [113]. The presynaptic activation of dopamine transmission is a key pharmacological property that mediates the wake-promoting effects of stimulants $[114,115]$. Thus, dopamine may play a role in sleep regulation at least indirectly through arousal mechanisms via the mesocorticolimbic dopamine system and possibly more directly via dopamine networks that are outside of the classic mesocorticolimbic dopamine system.

Opioid peptides. Alcohol at intoxicating doses releases opioid peptides that interact with the same receptors as opioid drugs [116]. Opioids increase wakefulness and decrease REM sleep $[3,117]$. In rats, low doses of morphine decrease sleep behavior, measured by EEGs of NREM sleep, REM sleep, and sleep efficiency [118]. The morphine-induced inhibition of REM sleep was localized to the medial pontine reticular formation in cats [119]. This observation was replicated in cats for selective $\mu$ but not $\delta$ or $\mathrm{k}$ opioid receptor agonists [120]. In rats, a $\mu$ opioid receptor agonist increased wakefulness when injected in the ventrolateral preoptic nucleus, and infusion of the selective $\mu$ opioid receptor antagonist CTAP in the ventrolateral preoptic nucleus promoted sleep, suggesting that endogenous $\mu$ opioid receptor agonists may participate in maintaining arousal via the ventrolateral preoptic nucleus [121]. However, the microinjection of $\mu$ opioid receptor agonists in the nucleus of the solitary tract produced SWS [122], suggesting a $\mu$ opioid receptor interaction with other sleepregulatory systems.

In terms of how endogenous opioids interact with sleep disturbances that are produced by AUD, chronic opioid use has been hypothesized to cause sleep disturbances and excessive daytime sleepiness and fatigue [123]. Sleep architecture studies have revealed different effects of morphine-like opioids that depend on the phase of opioid use [3]. During the induction phase, the use of morphine-like opioids significantly disrupts sleep, reduces REM sleep and SWS, and increases wakefulness and arousals from sleep. During the maintenance phase of opioid use, decreases in SWS and REM sleep and increases in wakefulness tend to normalize. During the withdrawal stage, significant insomnia is a major complaint during chronic opioid withdrawal, accompanied by frequent arousals and decreases in REM sleep [3]. During the protracted abstinence phase after chronic methadone use, TST significantly increased with rebound SWS and REM sleep that lasted for months following withdrawal with chronic methadone use [124].

Neurochemistry of sleep relevant to the withdrawal/negative affect stage

GABA within-system neuroadaptations. Sleep EEG effects in individuals with long-term alcohol dependence are opposite to those after acute alcohol administration. One possible mechanism involves within-system neuroadaptations even during the course of a bout of intoxication as discussed above. Chronic alcohol-induced alterations of the responsiveness of GABA mechanisms include the allosteric modification of GABA receptors $[7,8]$ and a reduction of $G A B A_{A}$ receptor function $[7,125]$ in rodent models of alcohol dependence. Thus, the downregulation of brainstem GABAergic systems following the development of alcohol dependence leads to the diminished activity of REM-off systems and subsequently a greater propensity for REM sleep. The downregulation of GABA systems could also partially explain the decrease in both delta power and the amplitude of evoked delta responses in abstinent alcoholics. However, there are other possible within-system mechanisms that may contribute to the disruption of sleep architecture during acute withdrawal and protracted abstinence. For example, the loss of dopamine function during acute withdrawal may contribute to malaise and hypoarousal that also could result in rebound sleepiness in late withdrawal.

Hypocretin between-system neuroadaptations. With regard to between-system neuroadaptations, all of the neurotransmitter systems that are hypothesized to act in the extended amygdala to promote negative emotional states are potential targets for between-system opponent processes that could contribute to sleep disturbances in the withdrawal/negative affect stage. These include (in order of sleep-related prominence) hypocretin, norepinephrine, glucocorticoids, and neuroimmune factors.

Hypocretin/orexin peptides have been implicated in sleep-wake regulation since their initial discovery [126]. They have wide projections in the brain [127], interacting with autonomic, neuroendocrine, and neuroregulatory systems [128-135]. Perhaps most well known is that the hypocretin system makes a key contribution to the etiology of narcolepsy. In two different animal models with impairments in the hypocretin/orexin system (i.e., genetic narcoleptic dogs with a mutation of the hypocretin receptor 2 [Hcrt-2] gene [136] and mice with a null mutation of the preprohypocretin gene that produces hypocretin- 1 and hypocretin-2 peptides [137]), symptoms of narcolepsy were observed, 
suggesting that impairment of the hypocretin/orexin system may underlie the syndrome of human narcolepsy. Human narcoleptic patients presented dramatic reductions (85-95\%) of cerebrospinal fluid hypocretin-1 [138] and the number of hypocretin neurons $[139,140]$, leading to the hypothesis that narcolepsy could be related to the ongoing loss of hypocretin neurons [141].

Hypocretins modulate key sleep systems, including norepinephrine [130, 142-144] and acetylcholine [145]. Hypocretins also modulate serotonergic [146, 147], histaminergic [148], and dopaminergic systems $[149,150]$ and the hypothalamicpituitary-adrenal (HPA) axis [151-153]. The hypocretin/orexin system stabilizes the firing of brainstem neurons that control wakefulness and REM sleep (cholinergic in the LDT/PPT, noradrenergic in the locus coeruleus). Notably, hypocretin neurons discharge during waking, especially with movement [154, 155]. Thus, unsurprising is that when these neurons are lost, such as in narcolepsy, patients present excessive daytime sleepiness and frequent sleep attacks.

The hypocretin/orexin system is thought to be a key regulator that stabilizes the firing of brainstem neurons that control wakefulness [156]. The silencing of hypocretin neurons using optogenetics or DREADDs that allow the modulation of neural activity with the temporal resolution of several hours, induces sleep during the light phase but not during the dark phase $[157,158]$ (although this approach may also affect other neurotransmitter systems). This supports the hypothesis that the hypocretin system acts as a regulator of behavioral states by modulating the arousal threshold [126] so that the organism can maintain appropriate and adequate wakefulness to cope with fluctuations of external and internal environments [156]. The overactivation of hypocretin/orexin peptides during drug withdrawal may cause destabilization of the boundaries between arousal sleep states that are found in acute and protracted abstinence. Numerous rodent studies have shown that hypocretin-1 receptor antagonists decrease high levels of alcohol self-administration in alcohol-preferring rats, the motivation to seek alcohol, alcohol drinking in dependence, and the cueinduced reinstatement of alcohol seeking $[4,159,160]$.

Norepinephrine between-system neuroadaptations. Norepinephrine has long been associated with promoting wakefulness. This action of norepinephrine in vivo likely involves the activation of $a_{1}$ adrenergic receptors, in which drugs that antagonize $a_{1}$ adrenergic receptors facilitate sleep onset [161]. This is likely a postsynaptic action of norepinephrine, whereas $a_{2}$ adrenergic receptor antagonists, which presynaptically increase norepinephrine release, delay sleep. In contrast, $a_{2}$ adrenergic receptor agonists inhibit norepinephrine release and decrease wakefulness [161, 162]. Drugs that block the uptake of norepinephrine increase or prolong wakefulness [163]. Neurochemical microdialysis studies have shown that extracellular levels of norepinephrine decrease in the transition from wakefulness to sleep $[164,165]$, and lesions of neurons in the locus coeruleus decrease waking [166].

Noradrenergic systems have also long been associated with alcohol dependence. Adrenergic receptor antagonists decreased dependence-induced drinking in rats. Although the locus coeruleus may not be directly implicated in the negative emotional states that are associated with alcohol withdrawal and protracted abstinence, sub-coeruleus noradrenergic projections to the bed nucleus of the stria terminalis modulate negative emotional states that are associated with opioid withdrawal and protracted abstinence [167].

Glucocorticoids, CRF, and vasopressin between-system neuroadaptations. One of the major bodily responses to acute stress that is associated with alcohol withdrawal is an elevation of glucocorticoids and the concomitant activation of extrahypothalamic stress systems [10]. The chronic ingestion of alcohol leads to a blunted HPA response that reflects negative feedback on the hypothalamic control of the HPA axis by CRF. However, at the same time, glucocorticoids sensitize the extrahypothalamic CRF system in the extended amygdala [168]. Both of these responses can contribute to the effects of alcohol in the withdrawal/negative affect stage of the addiction cycle.

Excessive activation of the HPA axis induces sleep debt [169], and sleep debt increases cortisol levels [170]. Patients with insomnia without depression presented high levels of cortisol, mainly in the evening and at sleep onset [171]. In clinical practice, the use of pharmacological doses of glucocorticoids is associated with sleep disturbances [172]. When steroids were administered as a short-term treatment in a multicenter, placebo-controlled study for optic neuritis, insomnia was one of the most commonly reported side effects [173]. Others have seen in humans a marked drop of cortisol levels during napping, followed by a transient increase during the postnap period [174]. The administration of glucocorticoids in humans can significantly suppress REM sleep [175] and cause a modest increase in SWS [176]. Altogether, human studies suggest that the HPA axis may contribute to the initiation and perpetuation of chronic insomnia [170].

An increase in cortisol may also be a marker of CRF and norepinephrine activity during the night, particularly because glucocorticoids can drive extrahypothalamic CRF activation. The intracerebroventricular administration of CRF increases EEG frequency and wakefulness and decreases SWS [177]. Other studies that reported decreases in SWS with elevated cortisol levels may indicate excessive glucocorticoid receptor activation in the amygdala, presumably via CRF. These positive feedback effects are opposite to the known inhibitory actions on CRF that are found in the paraventricular nucleus of the hypothalamus and anterior pituitary [176].

Chronic exposure to excess glucocorticoids is a key part of Cushing's syndrome. Consistent alterations of sleep (e.g., decrease in SWS, increase in sleep latency, increase in wake time, decrease in REM latency, and increase in REM density) have been reported In Cushing's syndrome with PSG recordings [178]. Given the hormonal and affective profiles that are common in Cushing's syndrome and severe AUD, one could argue that the CRF-HPA axis may contribute to sleep disturbances that are associated with AUD, and sleep disturbances may contribute to dysregulation of the CRF-HPA axis in a feed-forward allostatic framework.

Arginine vasopressin (AVP) is also involved in the regulation of adrenocorticotropic hormone $(A C T H)$ secretion and consequent glucocorticoid release [179]. Similar to CRF, AVP serves extrahypothalamically as a neurotransmitter [180]. A human study reported the sleep-associated inhibition of stimulated ACTH and cortisol release, suggesting a period of lower responsiveness of the pituitaryadrenocortical axis to AVP during early sleep [181]. Given the parallels between CRF and AVP in controlling the HPA axis and sleep regulation and given the role of CRF, glucocorticoids, and vasopressin in excessive drinking that is associated with alcohol dependence $[168,182]$, one could speculate on similar parallels in extrahypothalamic control over sleep and possible alcohol interactions.

Neuroimmune between-system neuroadaptations. Cytokines are intercellular signaling peptides that are released by immune cells, neurons, and astrocytes and have been hypothesized to be activated during alcohol withdrawal $[95,183]$ and also influence sleep [161, 184], albeit via actions on possibly different circuits. During infections, bacterial cell wall products, such as lipopolysaccharide, may trigger the production of cytokines that then increase NREM sleep and reduce REM sleep [185]. Several cytokines, including interleukin-1 $\beta$ (IL-1 $\beta$ ) and tumor necrosis factor-a (TNFa), promote sleep $[184,186]$. The administration of IL-1 $\beta$ and TNF- $\alpha$ in the preoptic area in rats reduced firing rates of wake-active neurons and promoted NREM sleep. IL-1 $\beta$ injections in the locus coeruleus [187] and dorsal raphe nuclei [188] promoted NREM sleep $[184,189,190]$. A physiological role for IL-1 $\beta$ and TNF- $a$ 
signaling in sleep can be argued based on observations in which the blockade of IL-1 $\beta$ and TNF- $\alpha$ signaling via the deletion of their receptors reduced spontaneous NREM sleep [191, 192]. Consistent with this hypothesis, cytokine levels in young, healthy individuals peaked during sleep [193], and a temporal relationship was found between sleep and IL-1 $\beta$ activity [194]. In a study of circadian patterns in humans, IL- 6 was secreted at baseline in a biphasic circadian pattern, with a late-night peak [195].

A direct interaction between cytokines, sleep, and AUD was demonstrated by the observation that administration of the TNF-a antagonist etanercept led to the normalization of REM sleep in 18 abstinent alcoholics [196]. Cytokines have been implicated in negative emotional states that drive negative reinforcement in animal models of alcohol dependence [197] and may contribute to the activation of CRF systems in the extended amygdala during alcohol dependence [198].

Neuropeptide $Y$ and endocannabinoid between-system neuroadaptations. Both NPY and endocannabinoids have been implicated in neuroadaptations that are associated with the development and persistence of alcohol dependence. Both neurochemical systems have been hypothesized to serve as a buffer to the activation of the brain stress systems during acute and protracted abstinence in alcohol dependence [24, 199]. Animal and human studies have reported sleep-promoting effects of NPY [200]. In animal studies, NPY increased EEG synchronization and increased sleep continuity [201, 202]. One mechanism that was hypothesized for NPY's sleep-promoting effects was a decrease in norepinephrine in the locus coeruleus [201]. Others have reported increases in wakefulness, activity, and eating with intracerebroventricular and intra-lateral hypothalamic administration of NPY in rats but an effect that was limited to this behaviorally active state $[203,204]$. In humans, repeated intravenous NPY administration in young healthy subjects decreased sleep latency, decreased the first REM sleep period, and increased Stage 2 sleep time [205]. The secretion of cortisol and ACTH was blunted after NPY administration [205]. The sedative and anxiolytic-like effects of centrally administered NPY are consistent with its hypothesized anti-stress buffering role under environmental challenge and its hypothesized hypoactivity during alcohol withdrawal [206].

Marijuana and $\Delta^{9}$-tetrahydrocannabinol are well documented to increase sleep in humans [207]. Endocannabinoids also increase sleep. More specifically, exogenously administered $\mathrm{CB}_{1}$ receptor agonists enhance NREM sleep in rats and humans $[208,209]$. The administration of $\mathrm{CB}_{1}$ receptor antagonists increased wake time and reduced NREM sleep time in rats $[210,211]$. Anandamide administration in the PPT decreased wakefulness and increased SWS, and these effects were reversed by a $\mathrm{CB}_{1}$ receptor antagonist [212]. One hypothesis is that endocannabinoids act in the pons and medulla to enhance the release of acetylcholine [207].

In a study that employed a microanalysis approach to investigate the role of endocannabinoids in up-state/down-state transitions in sleep that were recorded from pyramidal neurons in the prefrontal cortex, the endocannabinoid system was shown to regulate upstates and sleep, serving as a neuromodulatory system that is intrinsic to cortical microcircuitry [213]. In this study, $\mathrm{CB}_{1}$ receptor knockout mice exhibited an increase in wakefulness as a result of reductions of NREM sleep and NREM bout duration. During recovery from forced sleep deprivation, the knockout mice exhibited a reduction of NREM delta power and an increase in sleep fragmentation, consistent with increases in cortical excitability. The authors hypothesized that local neuromodulatory systems may tune network activity by regulating both excitatory and inhibitory neurotransmission within local cortical circuits, in which the activation of $\mathrm{CB}_{1}$ receptor endocannabinoid signaling in layer 5 pyramidal neurons may serve to selectively decrease the efficacy of a subset of excitatory inputs [214]. Neuropeptide $Y$ and endocannabinoids have been hypothesized to buffer increases in stress-like responses and increases in drinking during alcohol withdrawal in animal models of alcohol dependence [206, 215, 216], suggesting a common parallel neurochemical substrate for alcohol withdrawalinduced changes in sleep and alcohol seeking, albeit through different neurocircuits. Thus, the same opponent-process neurochemical actions that are produced during between-system neuroadaptations in the withdrawal/negative affect stage may be paralleled by actions on sleep systems that contribute to sleep disturbances in the withdrawal/negative affect stage.

Neurochemistry of sleep relevant to the preoccupation/ anticipation stage

Glutamate. Glutamate neurons are ubiquitous in the brain and distributed throughout the forebrain and brainstem. They are hypothesized, together with GABA neurons, to comprise effector neurons that are associated with EEG changes that underlie sleepwake states. Glutamate has been proposed to be the main regulator of arousal [1]. For example, the glutamatergic medial parabrachial nucleus in the dorsal pontine tegmentum that projects via the basal forebrain to the cerebral cortex regulates arousal [217]. In REM sleep, REM-on brainstem nuclei that contain acetylcholine, glutamate, and GABA promote activity in the basal forebrain and cortex and induce muscle atonia and rapid eye movements [218]. Fos-labeled neurons in the sublaterodorsal tegmental nucleus that trigger REM sleep were shown to be glutamatergic, measured by vGlut2 expression [219]. Finally, based on the anatomical and biochemical properties of astrocytes, others have proposed a mechanism by which astrocytes play a role as an energy provider through the release of lactate that is used as an energy substrate by glutamatergic neurons [220]. These results indicate that glutamate is a key player that drives the wake portion of the sleep-wake state.

However, the role of glutamate as a presumed sleep-wake effector neuron is more complicated, given the functional heterogeneity and intermingling of glutamate cell types in multiple regions, such that the stimulation of all glutamate neurons in any region may have opposing effects [221]. Nevertheless, a microanalysis of different effector neurons of sleep-wake states showed that $20 \%$ of Wake-max active (discharge maximally) cells were entirely glutamate-containing and also assumed to give rise to projections into the brainstem reticular formation and possibly spinal cord to influence behavior and EMG activity indirectly [221]. Indeed, the photo- or chemostimulation of genetically tagged glutamate neurons commonly evokes cortical activation $[222,223]$, likely reflecting the fact that glutamate is a prominent neurotransmitter by Wake/Paradoxical Sleep-max active neurons [221].

Chronic alcohol has long been associated with the dysregulation of glutamate activity, in which increases in glutamate function are associated with prolonged abstinence [224, 225]. Given the key role of glutamate in the neurocircuitry of relapse [226], cellular effects of alcohol on glutamate systems during protracted abstinence may generalize to the neurocircuits that drive sleepwake transitions.

\section{RELATIONSHIP BETWEEN TREATING INSOMNIA IN AUD AND ABSTINENCE}

Insomnia and AUD

The previous section of this review focused on laboratory measures of sleep and showed that some PSG characteristics of sleep in AUD can persist for months or even years. However, insomnia is a subjective complaint, and its diagnosis does not require PSG to be conducted. Indeed, individuals with insomnia can sometimes have their symptoms masked by sleeping in an unfamiliar environment, such as a laboratory [227, 228].

The current definition of "insomnia disorder" is dissatisfaction with sleep despite having adequate opportunity for sleep that lasts 
156

for 3 months and occurs three or more times per week. Insomnia is defined by difficulties in initiating sleep and/or maintaining sleep and/or early-morning awakening with an inability to return to sleep, and these sleep disturbances must cause clinically significant distress or impairments in daytime functioning. Importantly in the context of insomnia in AUD patients, the DSM-5 removed the distinction that was made in previous versions of the DSM between primary insomnia and comorbid insomnia. Similarly, the recent International Classification of Sleep Disorders, 3rd edition [229], grouped the secondary categories of insomnia and several subtypes ("psychophysiological insomnia," "idiopathic insomnia," "inadequate sleep hygiene," and "paradoxical insomnia") into a single category of "chronic insomnia disorder." For both groups, the diagnosis is made independent of PSG and based entirely on subjective reports by the patient. Severity can be measured by such instruments as the Insomnia Severity Index [230], in which subjects rate the perceived severity of their problems, indicate how much they interfere with daytime function, indicate how noticeable the sleep issues are to others, and indicate the extent to which they are worried by the condition.

There is a higher prevalence of AUD in insomnia patients than in good sleepers. For example, Ford and Kamerow [231] reported nearly double the prevalence of AUD in insomnia (7.0\%) relative to those with no sleep complaints (3.8\%). Weissman et al. [232] reported similar differences, with $3.3 \%$ of insomnia patients having AUD vs. $1.8 \%$ of normal sleepers. Notably, in a crosssectional study of 1200 health maintenance organization members in Michigan, the prevalence of alcohol abuse or dependence was found to be $30 \%$ in those with insomnia. However, consistent with Ford and Kerow [231] and Weissman et al. [232], the genderadjusted odds ratio for AUD was $2.0(1.3-3.0)$ relative to those with no sleep disturbances [233].

Insomnia has a high prevalence in AUD [30]. Brower [234] compiled data from 13 studies across 3173 patients to yield a prevalence of $58.4 \%$, although there was a large amount of variance in the data that the authors ascribed to such factors as differences in sample characteristics and the definitions that were used for both alcohol problems and insomnia.

Insomnia can precede AUD [233] and is also a symptom of alcohol withdrawal in both acute and protracted abstinence. Brooks et al. [235] studied 33 AUD patients on admission, during and 1 week prior to discharge from a National Institutes of Health clinical research inpatient treatment program. Twenty-eight patients also participated in a postdischarge study visit 4-6 weeks after discharge. Although the proportion of patients with a Pittsburgh Sleep Quality Index score $>5$ decreased from predischarge (69.7\%) to postdischarge, both numbers were very high relative to the general population.

Persistent insomnia over months of abstinence has been observed in numerous studies [234]. In a study of 267 alcoholdependent patients who entered inpatient and outpatient programs, 103 (47\%) had baseline insomnia based on a questionnaire [236]. Even at the 6-month follow-up, 25\% (26 of 103) showed persistent insomnia despite abstinence for the previous 3 months [236]. Such persistent sleep abnormalities in AUD have been validated by PSG measures [94]. Sleep architecture, such as an increase in the percentage of Stage 1 sleep (N1 or light sleep), a decrease in the percentage of N3 or SWS (deep sleep), and an increase in REM\%, was observed up to 27 months $[80,94,234]$. These alterations of REM sleep, including an increase in REM\% and a decrease in REM latency (minutes from sleep onset to the first REM period), were characterized as an increase in REM sleep pressure [237]. Under these conditions, patients may experience an increase in dreaming and/or an increase in vivid dreaming [234]. Polysomnographic measures and subjective reports also predicted relapse (for review, see [234]), as did the use of alcohol or hypnotics to help sleep upon admission to treatment [238].
Sleep interactions may not be restricted to AUD; they may also extend to risky drinking. Insomnia can precede and predict alcohol use in adolescents [239]. Poor sleep quality and insufficient TST have been shown to exacerbate associations between college drinking and negative drinking consequences of risky drinking [240-242]. In a 2-month prospective study of 157 college drinkers, students who reported higher sleep-related functional impairment experienced consistently high levels of negative drinking consequences, regardless of their risky drinking levels [242]. For a review of the relationship between sleep problems and adolescent AUD, see Hasler et al. [243]. Alcohol problem severity may also predict sleep disturbances. For problem drinkers, alcohol problem severity was predictive of the Pittsburgh Sleep Quality Index global score for sleep disturbance [244]. Intervention research suggests that targeting sleep problems among college drinkers may result in a decrease in alcohol use and related consequences $[245,246]$.

\section{Treatment of insomnia and AUD}

Sleep measures have also been included in numerous treatment studies and can provide some insights into whether treating insomnia in AUD contributes to abstinence or whether treating alcohol addiction improves sleep. One can divide such studies into two categories: those in which a sleep medication is applied to subjects with AUD and those in which an AUD medication is applied to treat AUD. The former category answers the question about whether treating insomnia contributes to abstinence.

As reviewed by Brower [234] and Chakravorty et al. [31], a number of randomized controlled trials have demonstrated that the treatment of insomnia and the treatment of AUD can be dissociated (Table 8). Some treatments that improve sleep in alcohol-dependent patients have no effect on drinking [247-249] or even worsen drinking [250]. Cognitive behavior therapy was shown to improve sleep but not drinking in two studies [247, 248]. Two drugs that improved sleep but not alcohol drinking include quetiapine [249] and trazadone [250].

Another rationale for the treatment of sleep disorders in AUD is that, retrospectively, subjects with AUD reported the presence of insomnia prior to the onset of AUD [251]. Many sleep studies have also revealed that sleep disturbances predict subsequent alcohol consumption in adolescents and adults [233, 252, 253]. One hypothesis for this association is that subjects may self-medicate their insomnia with alcohol [254, 255]. Finally, another benefit of treating insomnia is that it may provide symptom relief, improve quality of life, and improve functioning [234, 256].

Some investigators have argued that brief behavioral therapies are the treatment of choice for continued sleep disturbances during protracted abstinence because they have long-lasting benefits without causing negative effects on drinking outcomes [234]. One could argue that medications may work more quickly but inevitably alter sleep architecture themselves and have side effects, all of which may worsen drinking outcomes. One approach would be to use Food and Drug Administration (FDA)-approved medications with the least risk of side effects, including abuse potential, such as ramelteon and low-dose doxepin [234]. Nonprescription antihistamines may also work for some patients as alternatives to doxepin, which is also thought to work through the histaminergic system.

\section{Treatment of AUD and insomnia}

One reasonable conclusion is that if risky drinking and AUD cause insomnia and disturbances in sleep architecture, then successfully treating AUD would also treat sleep disturbances. However, such data are limited, largely because of the lack of studies and paucity of effective treatments for AUD. Acamprosate was approved by the FDA in 2004 as a medication for the treatment of AUD [257]. European trials of acamprosate for the treatment of AUD found a significant benefit for the maintenance of abstinence following 
Table 8. Pharmacological and behavioral treatments for insomnia in alcohol dependence

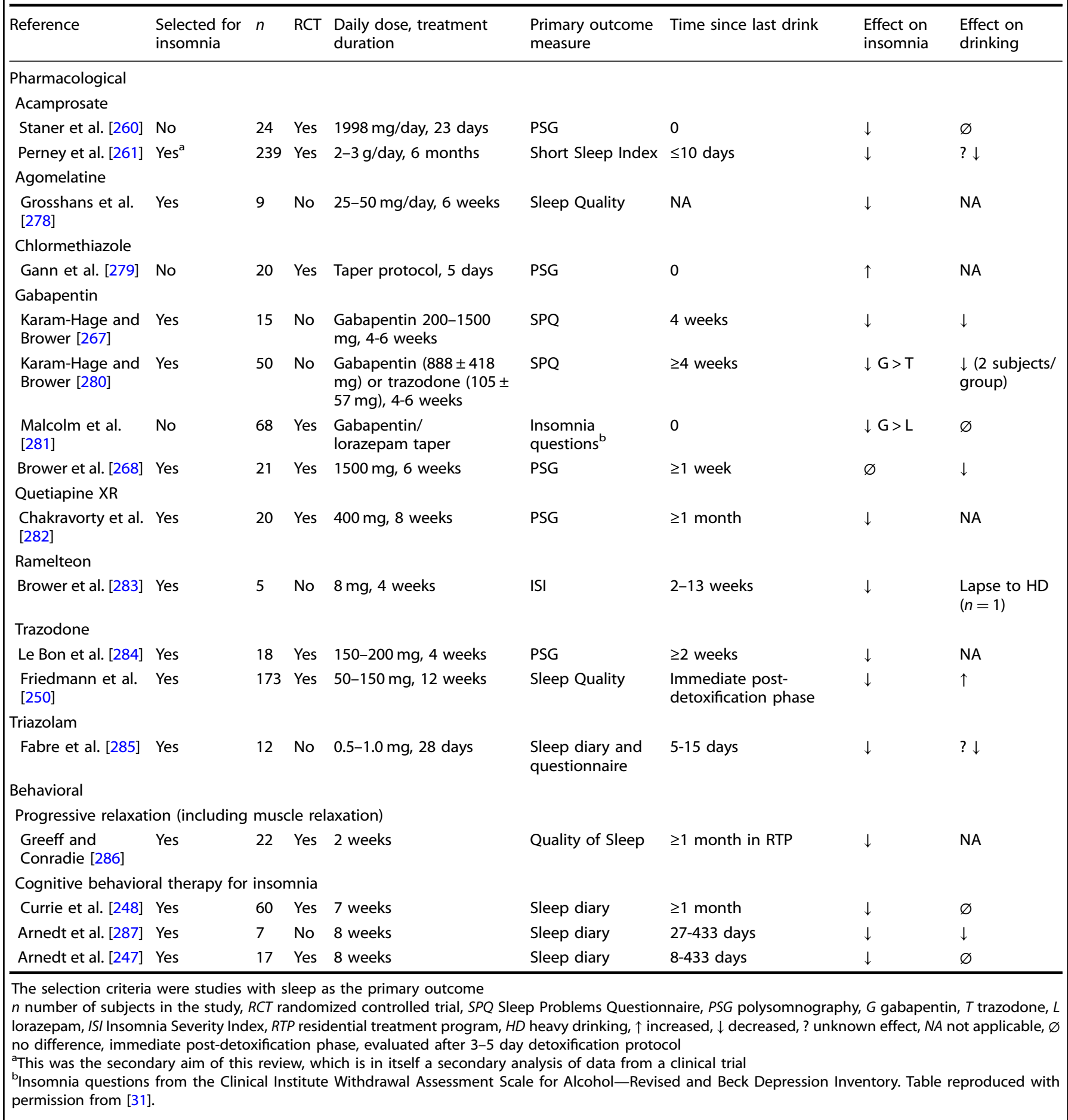

alcohol withdrawal in 15 of 18 randomized, double-blind, placebocontrolled trials [257]. In a large U.S. study, in which variables that were identified as important for treatment efficacy were applied as covariates and a subpopulation of individuals who were motivated to have a treatment goal of total abstinence at baseline were studied in a post hoc analyses, a significant linear treatment effect on the percentage of abstinent days was found that was consistent with prior positive studies [258]. Several studies, including a secondary analysis of the U.S. acamprosate study
[258], showed that acamprosate may help normalize AUD-related sleep disturbances [259-261]. From a sleep architecture perspective, two of these studies showed that acamprosate improved sleep continuity, restored Stage 3 sleep, and increased REM sleep latency, all of which are related to relapse to AUD. There are no published studies of sleep measures with naltrexone and AUD $[259,260]$. Sleep has not been studied in clinical trials of naltrexone, with the exception of one trial in which naltrexone was combined with gabapentin, thus confounding any 
conclusions about the effects of naltrexone on sleep parameters [262]. One study reported positive effects of topiramate on both sleep and drinking [263, 264].

Another drug that has been shown to improve sleep and decrease alcohol drinking is gabapentin [265]. Gabapentin is an anticonvulsant that is approved by the FDA for neurogenic pain and restless leg syndrome. It is also on the Veterans Administration formulary for use as a secondary treatment for AUD (https:// www.data.va.gov/dataset/va-national-formulary; accessed July 1, 2019). Gabapentin has been studied as a medication for the treatment of AUD, with positive results in double-blind, placebocontrolled human laboratory and clinical studies [258, 262, 265, 266]. In a landmark study, Mason et al. [265] showed that subjects who received gabapentin, particularly the $1800 \mathrm{mg}$ daily dose, had better drinking and sleep outcomes. Gabapentin had a significant linear dose effect on increasing the rates of complete abstinence and no heavy drinking and sleep as measured by the Pittsburgh Sleep Quality Index total score over the 12-week course of treatment relative to placebo [265]. Gabapentin is also effective specifically for insomnia that is associated with alcohol dependence $[267,268]$. One hypothesis is that gabapentin may be particularly helpful for substance use disorder patients who have an arousal, anxiety, and sleep disturbance component because it is used to treat restless leg syndrome and can improve drinking outcomes [234, 265]. Interestingly, the studies above that showed beneficial effects of gabapentin on AUD outcomes and sleep used immediate-release formulations, but a recent study that used an extended-release formulation did not show benefits for either AUD or sleep outcomes [269].

Nevertheless, given the paucity of data, it is difficult to dissociate the argument that treating sleep helps to treat alcohol addiction or that treating alcohol addiction helps to treat sleep disturbances. Obviously, the latter is a logical extension of considering sleep disturbances as a key symptom of protracted abstinence and a trigger for relapse. However, resolving these issues will require larger trials, more fine-grained analyses of sleep outcomes over time in clinical studies, the use of sleep-specific mediations (e.g., hypocretin receptor antagonists), and the advent of more medications that are effective in treating AUD. In this context, a clinical trial is about to begin in Australia, in which suvorexant, a hypocretin receptor antagonist, will be evaluated in terms of its ability to positively impact comorbid sleep disorder and AUD [270].

SUMMARY, CONCLUSIONS, AND OPEN RESEARCH QUESTIONS Alcohol use disorder is a devastating chronic disease that has major negative impacts on the lives of patients and their families. The pathway to the development of AUD often involves binge drinking to high levels of intoxication that leads to a compulsion to consume it, the loss of control in limiting consumption, and a transition to the "negative reinforcement side" when consumption occurs to stave off the negative consequences of withdrawal. This cascade of events that occurs over an extended period of time has thus been framed as a three-stage cycle: binge/intoxication, withdrawal/negative affect, and preoccupation/anticipation ("craving"). These stages map onto the dysregulation of functional domains of incentive salience/habits, negative emotional states, and executive function.

There is a substantial body of scientific work that supports the hypothesis that AUD is a brain neurocircuitry disorder and that neuroadaptations within specific motivational circuits play an important role in defining and perpetuating the disorder. During the binge/intoxication stage, pathological habits are at least partially attributable to the excessive engagement of reward circuitry, leading to high incentive salience for such factors as contextual cues that are related to alcohol consumption. The intoxicating and incentive salience effects of alcohol are underpinned by circuits that converge on the nucleus accumbens that involve GABA, glutamate, endogenous opioids, and dopamine. Glutamate and dopamine also act on the basal ganglia to support the development of pathological habits. The negative emotional state that is experienced in the withdrawal/negative affect stage is hypothesized to involve the extended amygdala, including the nucleus accumbens. The negative emotional effects may be related to the loss of function of endogenous opioids, GABA, and dopamine and the recruitment of arousal/stress factors, such as CRF, norepinephrine, hypocretin, and dynorphin, producing a gain in stress reactivity. The extended preoccupation/ anticipation stage in AUD that lasts long into abstinence involves compromised frontal cortical executive function and the dysregulation of substrates that mediate craving. These may be related to the dysregulation of glutamatergic projections from the frontal cortex and basolateral amygdala to the nucleus accumbens [27]. They may also be related to irreversible changes in the structure and function of the prefrontal cortex and neuronal connections that subserve circuits that link the prefrontal cortex to other parts of the brain [271, 272].

Sleep disturbances, alterations of sleep architecture, and the development of insomnia are almost ubiquitous in AUD. During the binge/intoxication stage, alcohol intoxication leads to a faster sleep onset, but the quality of subsequent sleep is poor relative to nights when no alcohol is consumed, with a substantial increase in wakefulness during the sleep period, especially later in the night. REM sleep is reduced early in the night, with some limited compensation later in the sleep period. Slow-wave sleep and EEG delta frequency increase early in the night following alcohol intoxication, but the normal benefits of SWS may not occur because of an increase in alpha activity that can be seen concurrently with an increase in delta (i.e., so-called alpha-delta sleep). The reduction of SOL and increase in delta activity may be related to the acute effects of alcohol on GABAergic systems that are associated with sleep regulation. The GABA receptor agonist properties of alcohol may also be at least partially responsible for the initial suppression of REM sleep.

Sleep effects in the withdrawal/negative affect stage are highly variable. Although there is a trend toward a decrease in SWS and some limited rebound in REM sleep when AUD individuals stop drinking, there appears to be limited recovery in sleep disturbances that are seen in AUD within the first 30 days of abstinence. The effects of withdrawal on sleep variables may also be related to the loss of alcohol as a positive allosteric modulator of $\mathrm{GABA}_{\mathrm{A}}$ receptors and the decrease in dopamine function. The overactivation of hypocretin/orexin peptides during drug withdrawal may also destabilize the boundaries between arousal sleep states that are found in acute and protracted abstinence. Other neurotransmitter and neuromodulator systems, such as norepinephrine, CRF, and cytokines, may also be involved.

The extended preoccupation/anticipation stage in long-term abstinent AUD individuals is associated with persistent sleep issues, including a longer sleep latency, more time awake during the night, a decrease in SWS, a decrease in delta EEG power and evoked delta activity, and an increase in REM sleep. Some of these factors, especially the reduction of spontaneous and evoked delta activity, may be related to the known, largely irreversible acceleration of brain shrinkage that is seen in AUD, especially in the frontal and prefrontal areas of the brain where delta activity is also predominant [75].

Clinically significant insomnia is highly prevalent in long-term abstinent AUD individuals and has been linked to an increase in the propensity to relapse. The dysregulation of glutamatergic systems that is observed in AUD is a likely substrate for some of the observed protracted and persistent sleep dysregulations. Several studies have shown that drugs that are used to treat AUD may also play a role in normalizing sleep in the acute withdrawal and extended abstinence periods. This is true for acamprosate, a 


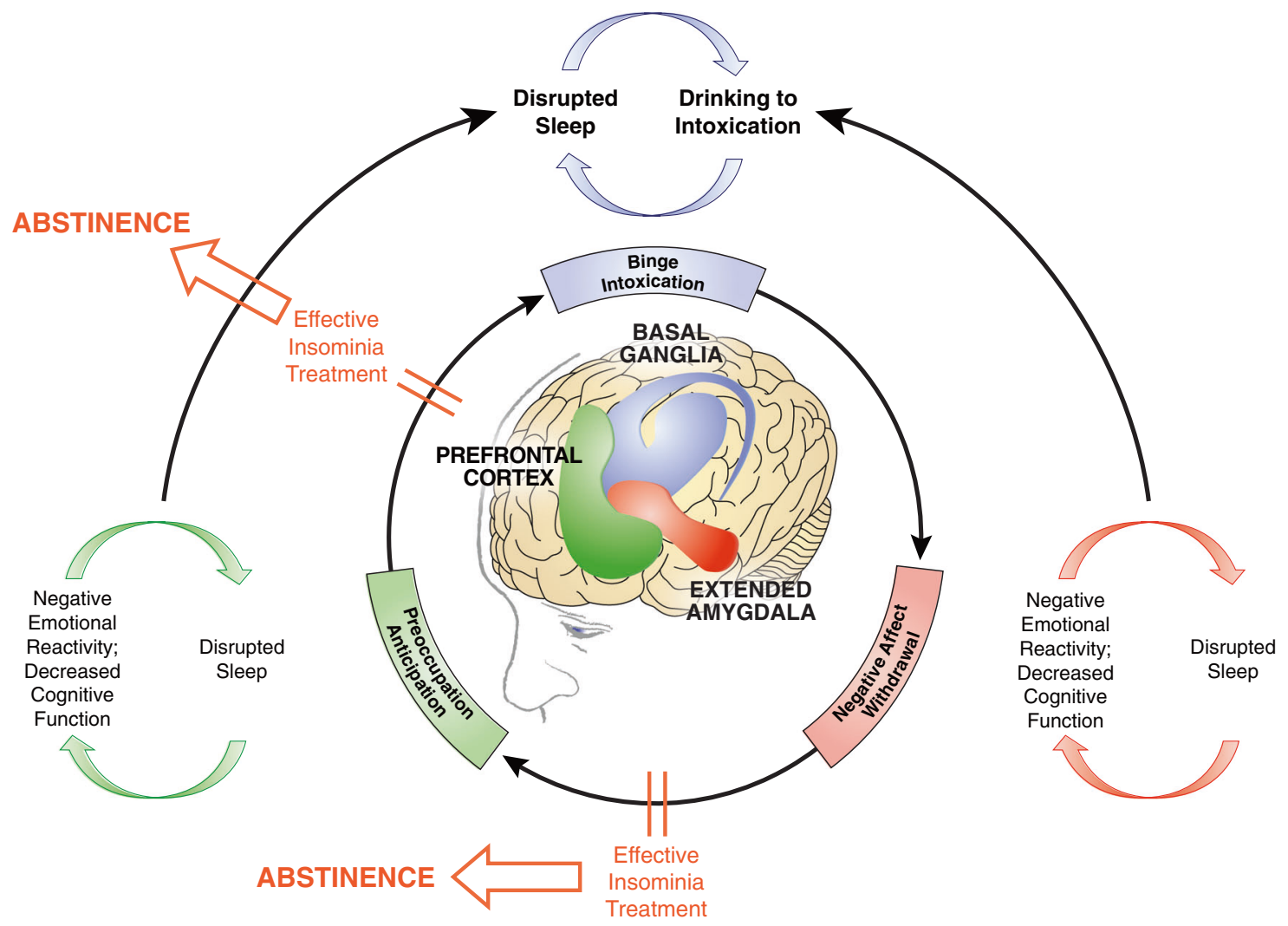

Fig. 4 Framework for how sleep dysregulation is caused by alcohol use disorder and itself causes or exacerbates alcohol use disorder. In the binge/intoxication stage, drinking to intoxication or binge drinking is hypothesized to disrupt sleep, and the consequent sleep disruption is hypothesized to drive further excessive alcohol drinking. In the withdrawal/negative affect stage, withdrawal disrupts sleep and may be a trigger for excessive drinking to provide relief from insomnia. In the preoccupation/anticipation stage, residual sleep dysregulation may set up relapse, particularly when paired with stress and/or alcohol-related cues. The treatment of sleep disturbances, particularly in the withdrawal/ negative affect stage and preoccupation/anticipation stage, is hypothesized to help promote abstinence and treat alcohol use disorder

glutamatergic allosteric modulator, and even more so for gabapentin, a modulator of voltage-dependent neuronal $\mathrm{Ca}^{2+}$ channels [273]. Given the link between insomnia and relapse and the exacerbation of emotional dysregulation, fatigue, and cognitive symptoms of withdrawal that are provided by sleep disturbance, effective treatments for insomnia in the withdrawal/ negative affect and preoccupation/anticipation stages could likely help lead to continued abstinence and prevent relapse.

More studies of the role of insomnia in abstinence and withdrawal are clearly warranted, especially in women. One particular aspect of such studies would be to systematically evaluate whether modulation of the brain stress systems, including the hypocretin/orexin system, has a positive impact on alcohol withdrawal and its associated sleep disturbances. The orexin/hypocretin system is composed of two neuropeptides, hypocretin-1 (orexin-A) and hypocretin-2 (orexin-B), and two excitatory G-protein coupled receptors, hypocretin-1 (orexin-1) and hypocretin-2 (orexin-2). Hypocretin-1 receptors appear to be more potent as a modulator of sleep and wakefulness [274]. The antagonism of hypocretin-1 receptors has been shown to prevent alcohol-seeking behavior in several animal models (for review, see [275]) and may directly address features in the withdrawal/ negative affect and preoccupation/anticipation stages of AUD. The use of dual hypocretin receptor antagonists, such as the FDAapproved drug suvorexant, could lead to improvements in abstinence outcomes in AUD. It is an effective treatment for insomnia [276] and has shown some promise in impacting addiction in preclinical models [277]. Other brain stress systems that contribute in animal studies to negative emotional states that drive negative reinforcement in the withdrawal/negative affect stage may either directly or indirectly impact sleep mechanisms, including norepinephrine, glucocorticoids, CRF, and even the dynorphin-k opioid receptor system. Finally, from a neurobiological perspective, sleep-inducing systems may buffer sleepdisrupting systems in parallel with buffers to the brain arousal stress systems, such as NPY, endocannabinoids, and oxytocin. Sleep is a modifiable behavior that may have a positive impact on abstinence in AUD and may lead to improvements in cardiovascular risk profiles.

From the perspective of translation to the clinical domain, much more work is needed to answer key questions about whether treating sleep disturbances in AUD is a key to treatment, particularly during protracted abstinence in the preoccupation/ anticipation stage and withdrawal/negative affect stage (Fig. 4). Sleep pathology clearly contributes to AUD pathology, and AUD pathology contributes to sleep pathology. This type of feedforward drive to a nonhomeostatic state fits well within an allostatic view of addiction, in which the hedonic set point resets at an abnormal, near pathological level that drives further alcohol seeking in a failed attempt to restore a normal hedonic set point in the form of misregulaton [15]. Sleep disturbances then become another part of allostatic load that drives the addiction process.

\section{FUNDING AND DISCLOSURE}

Dr. lan Colrain was supported by $\mathrm{NIH}$ grants AA024841 and AA021696. The authors declare no competing interests. 


\section{ACKNOWLEDGEMENTS}

We thank Michael Arends for assistance with manuscript preparation.

\section{ADDITIONAL INFORMATION}

Supplementary Information accompanies this paper at (https://doi.org/10.1038/ s41386-019-0446-0).

Publisher's note: Springer Nature remains neutral with regard to jurisdictional claims in published maps and institutional affiliations.

\section{REFERENCES}

1. Saper CB, Fuller PM. Wake-sleep circuitry: an overview. Curr Opin Neurobiol. 2017;44:186-92.

2. Su LD, Sun $C L$, Shen Y. Ethanol acutely modulates mGluR1-dependent long-term depression in cerebellum. Alcohol Clin Exp Res. 2010;34:1140-5.

3. Wang D, Teichtahl H. Opioids, sleep architecture and sleep-disordered breathing. Sleep Med Rev. 2007;11:35-46.

4. Lopez MF, Moorman DE, Aston-Jones G, Becker HC. The highly selective orexin/ hypocretin 1 receptor antagonist GSK1059865 potently reduces ethanol drinking in ethanol dependent mice. Brain Res. 2016;1636:74-80.

5. Colrain IM, Nicholas CL, Baker FC. Alcohol and the sleeping brain. Handb Clin Neurol. 2014;125:415-31.

6. Ebrahim IO, Shapiro CM, Williams AJ, Fenwick PB. Alcohol and sleep I: effects on normal sleep. Alcohol Clin Exp Res. 2013;37:539-49.

7. Kang MH, Spigelman I, Olsen RW. Alteration in the sensitivity of $G_{A B A_{A}}$ receptors to allosteric modulatory drugs in rat hippocampus after chronic intermittent ethanol treatment. Alcohol Clin Exp Res. 1998;22:2165-73.

8. Follesa P, Biggio F, Talani G, Murru L, Serra M, Sanna E, et al. Neurosteroids, $\mathrm{GABA}_{\mathrm{A}}$ receptors, and ethanol dependence. Psychopharmacology. 2006;186:267-80.

9. Valenzuela CF, Harris RA. Alcohol neurobiology. In: Lowinson JH, Ruiz P, Millman RB, Langrod JG, eds. Substance Abuse: A Comprehensive Textbook. Baltimore: Williams and Wilkins; 1997. p. 119-42.

10. Koob GF, Kreek MJ. Stress, dysregulation of drug reward pathways, and the transition to drug dependence. Am J Psychiatry. 2007;164:1149-59.

11. Rechtschaffen A, Kales A. A Manual of Standardised Terminology, Techniques and Scoring Systems for Sleep Stages of Human Subjects. Washington, DC: US Government Printing Office; 1968.

12. Iber C, Ancoli-Israel S, Chesson A, Quan S. The AASM Manual for the Scoring of Sleep and Associated Events: Rules, Terminology and Technical Specification. Darien IL: American Academy of Sleep Medicine; 2007.

13. American Psychiatric Association. Diagnostic and Statistical Manual of Mental Disorders. 5th ed. Washington DC: American Psychiatric Publishing; 2013.

14. American Psychiatric Association. Diagnostic and Statistical Manual: Mental Disorders. Washington DC: American Psychiatric Association; 1952.

15. Koob GF, Le Moal M. Drug abuse: hedonic homeostatic dysregulation. Science. 1997;278:52-58.

16. Kwako LE, Momenan R, Litten RZ, Koob GF, Goldman D. Addictions neuroclinical assessment: a neuroscience-based framework for addictive disorders. Biol Psychiatry. 2016;80:179-89.

17. Kwako LE, Schwandt ML, Ramchandani VA, Diazgranados N, Koob GF, Volkow ND et al. Neurofunctional domains derived from deep behavioral phenotyping in alcohol use disorder. Am J Psychiatry 2019; https://doi.org/10.1176/appi. ajp.2018.18030357

18. Koob GF. Allostatic view of motivation: implications for psychopathology. In: Bevins RA, Bardo MT, eds. Motivational Factors in the Etiology of Drug Abuse (series title: Nebraska Symposium on Motivation, vol 50). Lincoln NE: University of Nebraska Press; 2004. p. 1-18.

19. Koob GF, Volkow ND. Neurocircuitry of addiction. Neuropsychopharmacol Rev. 2010;35:217-38. Erratum in: 2010;35:1051.

20. Koob GF, Volkow ND. Neurobiology of addiction: a neurocircuitry analysis. Lancet Psychiatry. 2016;3:760-73.

21. Koob GF. Neurocircuitry of alcohol addiction: synthesis from animal models. In: Sullivan EV, Pfefferbaum A, eds. Alcohol and the Nervous System (series title: Handbook of Clinical Neurology, vol. 125). Amsterdam: Elsevier; 2014. p. 33-54.

22. Koob GF, Le Moal M. Drug addiction, dysregulation of reward, and allostasis. Neuropsychopharmacology. 2001;24:97-129.

23. Koob GF, Le Moal M. Addiction and the brain antireward system. Annu Rev Psychol. 2008;59:29-53.

24. Heilig M, Koob GF. A key role for corticotropin-releasing factor in alcohol dependence. Trends Neurosci. 2007;30:399-406.
25. Sullivan EV, Pfefferbaum A. Neurocircuitry in alcoholism: a substrate of disruption and repair. Psychopharmacology. 2005;180:583-94.

26. Goldstein RZ, Volkow ND. Drug addiction and its underlying neurobiological basis: neuroimaging evidence for the involvement of the frontal cortex. Am J Psychiatry. 2002;159:1642-52.

27. Martin-Fardon R, Weiss F. Modeling relapse in animals. Curr Top Behav Neurosci. 2013;13:403-32.

28. Rundell OH, Lester BK, Griffiths WJ, Williams HL. Alcohol and sleep in young adults. Psychopharmacologia. 1972;26:201-18.

29. National Institute on Alcohol Abuse and Alcoholism. Alcohol Metabolism (series title: Alcohol Alert, vol 35, PH 371). Bethesda MD: National Institute on Alcohol Abuse and Alcoholism; 1997. p. 51-71.

30. Brower KJ. Insomnia, alcoholism and relapse. Sleep Med Rev. 2003;7:523-39.

31. Chakravorty S, Chaudhary NS, Brower KJ. Alcohol dependence and its relationship with insomnia and other sleep disorders. Alcohol Clin Exp Res. 2016;40:2271-82.

32. Stone BM. Sleep and low doses of alcohol. Electro Clin Neurophysiol. 1980;48:706-9.

33. MacLean AW, Cairns J. Dose-response effects of ethanol on the sleep of young men. J Stud Alcohol. 1982;43:434-44.

34. Scrima L, Broudy M, Nay KN, Cohn MA. Increased severity of obstructive sleep apnea after bedtime alcohol ingestion: diagnostic potential and proposed mechanism of action. Sleep. 1982;5:318-28.

35. Williams DL, MacLean AW, Cairns J. Dose-response effects of ethanol on the sleep of young women. J Stud Alcohol. 1983;44:515-23.

36. Roehrs T, Yoon J, Roth T. Nocturnal and next-day effects of ethanol and basal level of sleepiness. Hum Psychopharmacol. 1991;6:307-12.

37. Roehrs $T$, Papineau K, Rosenthal $L$, Roth $T$. Ethanol as a hypnotic in insomniacs: self administration and effects on sleep and mood. Neuropsychopharmacology. 1999;20:279-86.

38. Van Reen E, Jenni OG, Carskadon MA. Effects of alcohol on sleep and the sleep electroencephalogram in healthy young women. Alcohol Clin Exp Res. 2006;30:974-81.

39. Feige B, Gann H, Brueck R, Hornyak M, Litsch S, Hohagen F, et al. Effects of alcohol on polysomnographically recorded sleep in healthy subjects. Alcohol Clin Exp Res. 2006;30:1527-37.

40. Arnedt JT, Rohsenow DJ, Almeida AB, Hunt SK, Gokhale M, Gottlieb DJ, et al. Sleep following alcohol intoxication in healthy, young adults: effects of sex and family history of alcoholism. Alcohol Clin Exp Res. 2011b;35:870-8.

41. Sagawa $\mathrm{Y}$, Kondo $\mathrm{H}$, Matsubuchi N, Takemura $\mathrm{T}$, Kanayama $\mathrm{H}$, Kaneko $\mathrm{Y}$, et al. Alcohol has a dose-related effect on parasympathetic nerve activity during sleep. Alcohol Clin Exp Res. 2011;35:2093-2100.

42. Chan JK, Trinder J, Andrewes HE, Colrain IM, Nicholas CL. The acute effects of alcohol on sleep architecture in late adolescence. Alcohol Clin Exp Res. 2013;37:1720-8.

43. Nicholson AN, Pascoe PA. Hypnotic activity of an imidazo-pyridine (zolpidem). Br J Clin Pharm. 1986;21:205-11.

44. McCann CC, Quera-Salva MA, Boudet J, Frisk M, Barthouil $P$, Borderies $P$, et al. Effect of zolpidem during sleep on ventilation and cardiovascular variables in normal subjects. Fundam Clin Pharm. 1993;7:305-10.

45. Prinz PN, Roehrs TA, Vitaliano PP, Linnoila M, Weitzman ED. Effect of alcohol on sleep and nighttime plasma growth hormone and cortisol concentrations. J Clin Endocrinol Metab. 1980;51:759-64.

46. Landolt HP, Roth C, Dijk DJ, Borbély AA. Late-afternoon ethanol intake affects nocturnal sleep and the sleep EEG in middle-aged men. J Clin Psychopharmacol. 1996;16:428-36.

47. Loomis AL, Harvey EN, Hobart G. Potential rhythms of the cerebral cortex during sleep. Science. 1935;81:597-8.

48. Loomis AL, Harvey EN, Hobart G. Electrical potentials of the human brain. J Exp Psychol. 1936;19:249-79.

49. Loomis AL, Harvey EN, Hobart G. Cerebral processes during sleep as studied by human brain potentials. Science. 1937;85:443-4.

50. Dijk DJ, Brunner DP, Aeschbach D, Tobler I, Borbély AA. The effects of ethanol on human sleep EEG power spectra differ from those of benzodiazepine receptor agonists. Neuropsychopharmacology. 1992;7:225-32.

51. Chan JK, Trinder J, Colrain IM, Nicholas CL. The acute effects of alcohol on sleep electroencephalogram power spectra in late adolescence. Alcohol Clin Exp Res. 2015;39:291-9

52. Moldofsky H. Sleep and pain. Sleep Med Rev. 2001;5:385-96.

53. Johnson LC, Burdick JA, Smith J. Sleep during alcohol intake and withdrawal in the chronic alcoholic. Arch Gen Psychiatry. 1970;22:406-18.

54. Allen RP, Wagman A, Faillace LA, Mclntosh M. Electroencephalographic (EEG) sleep recovery following prolonged alcohol intoxication in alcoholics. J Nerv Ment Dis. 1971;153:424-33. 
55. Gross MM, Goodenough DR, Hastey J, Lewis E. Experimental study of sleep in chronic alcoholics before, during, and after four days of heavy drinking with a nondrinking comparison. Ann N Y Acad Sci. 1973;215:254-65.

56. Lester BK, Rundell OH, Cowden LC, Williams HL. Chronic alcoholism, alcohol and sleep. In: Gross MM, ed. Alcohol Intoxication and Withdrawal (series title: Advances in Experimental Medicine and Biology, vol 59). New York, NY: Plenum Press; 1975. p. 261-79.

57. Wagman AM, Allen RP. Effects of alcohol ingestion and abstinence on slow wave sleep of alcoholics. Adv Exp Med Biol. 1975;59:453-66.

58. Gross MM, Hastey JM. Slow wave sleep and carry-over of functional tolerance and physical dependence in alcoholics. Adv Exp Med Biol. 1975;59:477-93.

59. Arnedt JT, Conroy DA, Brower KJ. Treatment options for sleep disturbances during alcohol recovery. J Addict Dis. 2007a;26:41-54.

60. Brower KJ, Perron BE. Prevalence and correlates of withdrawal-related insomnia among adults with alcohol dependence: results from a national survey. Am J Addict. 2010;19:238-44.

61. Rundell $\mathrm{OH}$, Williams $\mathrm{HL}$, Lester BK. Sleep in alcoholic patients: longitudinal findings. Adv Exp Med Biol. 1977;85B:389-402.

62. Snyder S, Karacan I. Sleep patterns of sober chronic alcoholics. Neuropsychobiology. 1985;13:97-100.

63. Gillin JC, Smith TL, Irwin M, Kripke DF, Schuckit M. EEG sleep studies in "pure" primary alcoholism during subacute withdrawal: relationships to normal controls, age, and other clinical variables. Biol Psychiatry. 1990;27:477-88.

64. Thompson PM, Gillin JC, Golshan S, Irwin M. Polygraphic sleep measures differentiate alcoholics and stimulant abusers during short-term abstinence. Biol Psychiatry. 1995;38:831-6.

65. Drummond SP, Gillin JC, Smith TL, DeModena A. The sleep of abstinent pure primary alcoholic patients: natural course and relationship to relapse. Alcohol Clin Exp Res. 1998;22:1796-802.

66. Irwin M, Miller C, Gillin JC, Demodena A, Ehlers CL. Polysomnographic and spectral sleep EEG in primary alcoholics: an interaction between alcohol dependence and African-American ethnicity. Alcohol Clin Exp Res. 2000;24:1376-84.

67. Irwin M, Gillin JC, Dang J, Weissman J, Phillips E, Ehlers CL. Sleep deprivation as a probe of homeostatic sleep regulation in primary alcoholics. Biol Psychiatry. 2002;51:632-41.

68. Kuhlwein E, Hauger RL, Irwin MR. Abnormal nocturnal melatonin secretion and disordered sleep in abstinent alcoholics. Biol Psychiatry. 2003;54:1437-43.

69. Gann H, van Calker D, Feige B, Cloot O, Brück R, Berger M, et al. Polysomnographic comparison between patients with primary alcohol dependency during subacute withdrawal and patients with a major depression. Eur Arch Psychiatry Clin Neurosci. 2004b;254:263-71.

70. Feige B, Scaal S, Hornyak M, Gann H, Riemann D. Sleep electroencephalographic spectral power after withdrawal from alcohol in alcohol-dependent patients. Alcohol Clin Exp Res. 2007;31:19-27.

71. Irwin MR, Bjurstrom MF, Olmstead R. Polysomnographic measures of sleep in cocaine dependence and alcohol dependence: implications for age-related loss of slow wave, stage 3 sleep. Addiction. 2016;111:1084-92.

72. Singh LK, Nizamie SH, Tikka SK. Sleep architecture and EEG power spectra in recently detoxified alcohol dependent patients. Asian J Psychiatr. 2018;32:126-36.

73. Colrain IM. The K-complex: a 7-decade history. Sleep. 2005;28:255-73.

74. Colrain IM, Crowley KE, Nicholas CL, Afifi L, Baker FC, Padilla M, et al. Sleep evoked delta frequency responses show a linear decline in amplitude across the adult lifespan. Neurobiol Aging. 2010;31:874-83.

75. Colrain IM, Sullivan EV, Rohlfing T, Baker FC, Nicholas CL, Padilla ML, et al. Independent contributions of cortical gray matter, aging, sex and alcoholism to K-complex amplitude evoked during sleep. Sleep. 2011;34:787-95.

76. Willoughby AR, de Zambotti M, Baker FC, Colrain IM. Partial K-complex recovery following short-term abstinence in individuals with alcohol use disorder. Alcohol Clin Exp Res. 2015;39:1417-24.

77. Williams $\mathrm{HL}$, Rundell $\mathrm{OH}$ Jr. Altered sleep physiology in chronic alcoholics: reversal with abstinence. Alcohol Clin Exp Res. 1981;5:318-25.

78. Le Bon O, Verbanck P, Hoffmann G, Murphy JR, Staner L, De Groote D, et al. Sleep in detoxified alcoholics: impairment of most standard sleep parameters and increased risk for sleep apnea, but not for myoclonias - a controlled study. J Stud Alcohol. 1997;58:30-36.

79. Irwin MR, Valladares EM, Motivala S, Thayer JF, Ehlers CL. Association between nocturnal vagal tone and sleep depth, sleep quality, and fatigue in alcohol dependence. Psychosom Med. 2006;68:159-66.

80. Colrain IM, Turlington S, Baker FC. Impact of alcoholism on sleep architecture and EEG power spectra in men and women. Sleep. 2009b;32:1341-52.

81. Nicholas $\mathrm{CL}$, Sullivan EV, Pfefferbaum A, Trinder J, Colrain IM. The effects of alcoholism on auditory evoked potentials during sleep. J Sleep Res. 2002;11:247-53.
82. American Psychiatric Association. Diagnostic and Statistical Manual of Mental Disorders. 4th edition. Washington DC: American Psychiatric Press; 1994.

83. Colrain IM, Crowley KE, Nicholas CL, Padilla M, Baker FC. The impact of alcoholism on sleep evoked delta frequency responses. Biol Psychiatry. 2009a;66:177-84.

84. Colrain IM, Padilla ML, Baker FC. Partial recovery of alcohol dependence-related deficits in sleep evoked potentials following 12 months of abstinence. Front Neurol. 2012;3:13.

85. Ely M, Hardy R, Longford NT, Wadsworth ME. Gender differences in the relationship between alcohol consumption and drink problems are largely accounted for by body water. Alcohol Alcohol. 1999;34:894-902.

86. Keyes KM, Grant BF, Hasin DS. Evidence for a closing gender gap in alcohol use, abuse, and dependence in the United States population. Drug Alcohol Depend. 2008;93:21-29.

87. Agabio R, Pisanu C, Gessa GL, Franconi F. Sex differences in alcohol use disorder. Curr Med Chem. 2017;24:2661-70.

88. Patrick ME, Terry-McElrath YM, Lanza ST, Jager J, Schulenberg JE, O'Malley PM. Shifting age of peak binge drinking prevalence: historical changes in normative trajectories among young adults aged 18 to 30. Alcohol Clin Exp Res. 2019:43:287-98.

89. Walter H, Gutierrez K, Ramskogler K, Hertling I, Dvorak A, Lesch OM. Genderspecific differences in alcoholism: implications for treatment. Arch Women's Ment Health. 2003;6:253-8.

90. Agabio R, Campesi I, Pisanu C, Gessa GL, Franconi F. Sex differences in substance use disorders: focus on side effects. Addict Biol. 2016;21:1030-42.

91. Roswall N, Weiderpass E. Alcohol as a risk factor for cancer: existing evidence in a global perspective. J Prev Med Public Health. 2015;48:1-9.

92. Peters TJ, Millward LM, Foster J. Quality of life in alcohol misuse: comparison of men and women. Arch Women's Ment Health. 2003;6:239-43.

93. Manber R, Baker FC, Gress JL. Sex differences in sleep and sleep disorders: a focus on women's sleep. Int J Sleep Disord. 2006;1:7-15.

94. Brower KJ, Aldrich MS, Robinson EA, Zucker RA, Greden JF. Insomnia, selfmedication, and relapse to alcoholism. Am J Psychiatry. 2001;158:399-404.

95. España RA, Scammell TE. Sleep neurobiology from a clinical perspective. Sleep. 2011;34:845-58.

96. Fuller PM, Gooley JJ, Saper CB. Neurobiology of the sleep-wake cycle: sleep architecture, circadian regulation, and regulatory feedback. J Biol Rhythms. 2006;21:482-93.

97. McCarley RW, Hobson JA. Neuronal excitability modulation over the sleep cycle: a structural and mathematical model. Science. 1975;189:58-60.

98. Steriade M, McCormick DA, Sejnowski TJ. Thalamocortical oscillations in the sleeping and aroused brain. Science 1993:262:679-85.

99. Steriade M. Cellular substrates of brain rhythms. In: Niedermeyer E, Lopes da Silva F, eds. Electroencephalography: Basic Principles, Clinical Applications and Related Fields. Baltimore: Williams and Wilkins; 1999. p. 28-75.

100. Kelm MK, Criswell HE, Breese GR. Ethanol-enhanced GABA release: a focus on $G$ protein-coupled receptors. Brain Res Rev. 2011;65:113-23.

101. Hughes SW, Cope DW, Blethyn KL, Crunelli V. Cellular mechanisms of the slow $(<1 \mathrm{~Hz})$ oscillation in thalamocortical neurons in vitro. Neuron. 2002; 33:947-58.

102. Steriade M. Cellular substrates of brain rhythms. In: Niedermeyer E, Lopes da Silva F, eds. Electroencephalography: Basic Principles, Clinical Applications and Related Fields. Baltimore: Williams and Wilkins; 1993. p. 27-62.

103. Johnson LC, Hanson K, Bickford RG. Effect of flurazepam on sleep spindles and K-complexes. Electro Clin Neurophysiol. 1976;40:67-77.

104. Johnson LC, Seales DM, Naitoh P, Church MW, Sinclair M. The effects of flurazepam hydrochloride on brain electrical activity during sleep. Electro Clin Neurophysiol. 1979;47:309-21.

105. McCarley RW. Neurobiology of REM sleep. Handb Clin Neurol. 2011;98:151-71.

106. Belin D, Everitt BJ. Cocaine seeking habits depend upon dopamine-dependent serial connectivity linking the ventral with the dorsal striatum. Neuron. 2008;57:432-41.

107. Miller JD, Farber J, Gatz P, Roffwarg H, German DC. Activity of mesencephalic dopamine and non-dopamine neurons across stages of sleep and walking in the rat. Brain Res. 1983;273:133-41.

108. Steinfels GF, Heym J, Strecker RE, Jacobs BL. Behavioral correlates of dopaminergic unit activity in freely moving cats. Brain Res. 1983;258:217-28.

109. Jones BE, Bobillier $P$, Pin $C$, Jouvet $M$. The effect of lesions of catecholaminecontaining neurons upon monoamine content of the brain and EEG and behavioral waking in the cat. Brain Res. 1973;58:157-77.

110. Rye DB, Jankovic J. Emerging views of dopamine in modulating sleep/wake state from an unlikely source: PD. Neurology. 2002;58:341-6.

111. Paus S, Brecht HM, Köster J, Seeger G, Klockgether T, Wüllner U. Sleep attacks, daytime sleepiness, and dopamine agonists in Parkinson's disease. Mov Disord. 2003;18:659-67. 
112. Isaac SO, Berridge CW. Wake-promoting actions of dopamine D1 and D2 receptor stimulation. J Pharm Exp Ther. 2003;307:386-94.

113. Lu J, Saper CB. Identification of wake-active dopaminergic neurons. Sleep. 2002;25:A290.

114. Kanbayashi T, Honda K, Kodama T, Mignot E, Nishino S. Implication of dopaminergic mechanisms in the wake-promoting effects of amphetamine: a study of D- and L-derivatives in canine narcolepsy. Neuroscience. 2000;99:651-9.

115. Nishino S, Mao J, Sampathkumaran R, Shelton J. Increased dopaminergic transmission mediates the wake-promoting effects of CNS stimulants. Sleep Res. 1998;1:49-61.

116. Cui C, Koob GF. Titrating tipsy targets: the neurobiology of low-dose alcohol. Trends Pharm Sci. 2017;38:556-68.

117. Kay DC, Eisenstein RB, Jasinski DR. Morphine effects on human REM state, waking state and NREM sleep. Psychopharmacologia. 1969;14:404-16.

118. Bronzino JD, Kelly ML, Cordova C, Gudz M, Oley N, Stern WC, et al. Amplitude and spectral quantification of the effects of morphine on the cortical EEG of the rat. Electro Clin Neurophysiol. 1982;53:14-26.

119. Keifer JC, Baghdoyan HA, Lydic R. Sleep disruption and increased apneas after pontine microinjection of morphine. Anesthesiology. 1992;77:973-82.

120. Cronin A, Keifer JC, Baghdoyan HA, Lydic R. Opioid inhibition of rapid eye movement sleep by a specific mu receptor agonist. $\mathrm{Br} J$ Anaesth. 1995;74:188-92.

121. Greco MA, Fuller PM, Jhou TC, Martin-Schild S, Zadina JE, Hu Z, et al. Opioidergic projections to sleep-active neurons in the ventrolateral preoptic nucleus. Brain Res. 2008;1245:96-107.

122. Reinoso-Barbero F, de Andres I. Effects of opioid microinjections in the nucleus of the solitary tract on the sleep-wakefulness cycle states in cats. Anesthesiology. 1995;82:144-52.

123. Moore P, Dimsdale JE. Opioids, sleep, and cancer-related fatigue. Med Hypotheses. 2002;58:77-82.

124. Martin WR, Jasinski DR, Haertzen CA, Kay DC, Jones BE, Mansky PA, et al. Methadone: a reevaluation. Arch Gen Psychiatry. 1973;28:286-95.

125. Mihic SJ, Harris RA. Alcohol actions at the $G A B A_{A}$ receptor/chloride channels complex. In: Deitrich RA, Erwin G, eds. Pharmacological Effects of Ethanol on the Nervous System. Boca Raton: CRC Press; 1995. p. 51-71.

126. Sutcliffe JG, de Lecea L. The hypocretins: setting the arousal threshold. Nat Rev Neurosci. 2002;3:339-49.

127. Peyron C, Tighe DK, van den Pol AN, de Lecea L, Heller HC, Sutcliffe JG, et al. Neurons containing hypocretin (orexin) project to multiple neuronal systems. J Neurosci. 1998;18:9996-10015.

128. Chen CT, Hwang LL, Chang JK, Dun NJ. Pressor effects of orexins injected intracisternally and to rostral ventrolateral medulla of anesthetized rats. Am J Physiol Regul Integr Comp Physiol. 2000;278:R692-R697.

129. Date $Y$, Mondal MS, Matsukura S, Ueta Y, Yamashita H, Kaiya H, et al. Distribution of orexin/hypocretin in the rat median eminence and pituitary. Brain Res Mol Brain Res. 2000;76:1-6.

130. Hagan JJ, Leslie RA, Patel S, Evans ML, Wattam TA, Holmes S, et al. Orexin A activates locus coeruleus cell firing and increases arousal in the rat. Proc Natl Acad Sci USA. 1999;96:10911-6.

131. Ida T, Nakahara K, Murakami T, Hanada R, Nakazato M, Murakami N. Possible involvement of orexin in the stress reaction in rats. Biochem Biophys Res Commun. 2000;270:318-23.

132. Malendowicz LK, Tortorella C, Nussdorfer GG. Orexins stimulate corticosterone secretion of rat adrenocortical cells, through the activation of the adenylate cyclase-dependent signaling cascade. J Steroid Biochem Mol Biol. 1999;70:185-8.

133. Nowak KW, Maćkowiak P, Switońska MM, Fabiś M, Malendowicz LK. Acute orexin effects on insulin secretion in the rat: in vivo and in vitro studies. Life Sci. 2000;66:449-54.

134. Samson WK, Gosnell B, Chang JK, Resch ZT, Murphy TC. Cardiovascular regulatory actions of the hypocretins in brain. Brain Res. 1999;831:248-53.

135. Shirasaka T, Kunitake T, Takasaki M, Kannan H. Neuronal effects of orexins: relevant to sympathetic and cardiovascular functions. Regul Pept. 2002;104:91-95.

136. Lin L, Faraco J, Li R, Kadotani H, Rogers W, Lin X, et al. The sleep disorder canine narcolepsy is caused by a mutation in the hypocretin (orexin) receptor 2 gene. Cell. 1999;98:365-76.

137. Chemelli RM, Willie JT, Sinton CM, Elmquist JK, Scammell T, Lee C, et al. Narcolepsy in orexin knockout mice: molecular genetics of sleep regulation. Cell. 1999:98:437-51.

138. Nishino S, Ripley B, Overeem S, Lammers GJ, Mignot E. Hypocretin (orexin) deficiency in human narcolepsy. Lancet. 2000;355:39-40.

139. Peyron C, Faraco J, Rogers W, Ripley B, Overeem S, Charnay Y, et al. A mutation in a case of early onset narcolepsy and a generalized absence of hypocretin peptides in human narcoleptic brains. Nat Med. 2000;6:991-7.
140. Thannickal TC, Moore RY, Nienhuis R, Ramanathan L, Gulyani S, Aldrich M, et al. Reduced number of hypocretin neurons in human narcolepsy. Neuron. 2000;27:469-74.

141. van den Pol AN. Narcolepsy: a neurodegenerative disease of the hypocretin system? Neuron. 2000;27:415-8.

142. Bourgin $P$, Huitrón-Résendiz $S$, Spier $A D$, Fabre $V$, Morte $B$, Criado $J R$, et al. Hypocretin-1 modulates rapid eye movement sleep through activation of locus coeruleus neurons. J Neurosci. 2000;20:7760-5.

143. Horvath TL, Peyron C, Diano S, Ivanov A, Aston-Jones G, Kilduff TS, et al. Hypocretin (orexin) activation and synaptic innervation of the locus coeruleus noradrenergic system. J Comp Neurol. 1999;415:145-59.

144. Ivanov A, Aston-Jones G. Hypocretin/orexin depolarizes and decreases potassium conductance in locus coeruleus neurons. Neuroreport. 2000; 11:1755-8.

145. Burlet S, Tyler CJ, Leonard CS. Direct and indirect excitation of laterodorsal tegmental neurons by hypocretin/orexin peptides: implications for wakefulness and narcolepsy. J Neurosci. 2002;22:2862-72.

146. Brown RE, Sergeeva OA, Eriksson KS, Haas HL. Convergent excitation of dorsal raphe serotonin neurons by multiple arousal systems (orexin/hypocretin, histamine and noradrenaline). J Neurosci. 2002;22:8850-9.

147. Brown RE, Sergeeva O, Eriksson KS, Haas HL. Orexin A excites serotonergic neurons in the dorsal raphe nucleus of the rat. Neuropharmacology. 2001;40:457-9.

148. Eriksson KS, Sergeeva O, Brown RE, Haas HL. Orexin/hypocretin excites the histaminergic neurons of the tuberomammillary nucleus. I Neurosci. 2001:21:9273-9.

149. Nakamura T, Uramura K, Nambu T, Yada T, Goto K, Yanagisawa M, et al. Orexininduced hyperlocomotion and stereotypy are mediated by the dopaminergic system. Brain Res. 2000;873:181-7.

150. Korotkova TM, Sergeeva OA, Eriksson KS, Haas HL, Brown RE. Excitation of ventral tegmental area dopaminergic and nondopaminergic neurons by orexins/hypocretins. J Neurosci. 2003;23:7-11.

151. Jaszberenyi M, Bujdosó E, Pataki I, Telegdy G. Effects of orexins on the hypothalamic-pituitary-adrenal system. J Neuroendocr. 2000;12:1174-8.

152. Kuru M, Ueta Y, Serino R, Nakazato M, Yamamoto Y, Shibuya I, et al. Centrally administered orexin/hypocretin activates HPA axis in rats. Neuroreport. 2000;11:1977-80.

153. Stricker-Krongrad A, Beck B. Modulation of hypothalamic hypocretin/orexin mRNA expression by glucocorticoids. Biochem Biophys Res Commun. 2002:296:129-33.

154. Lee MG, Hassani OK, Jones BE. Discharge of identified orexin/hypocretin neurons across the sleep-waking cycle. J Neurosci. 2005;25:6716-20.

155. Mileykovskiy BY, Kiyashchenko LI, Siegel JM. Behavioral correlates of activity in identified hypocretin/orexin neurons. Neuron. 2005;46:787-98.

156. de Lecea L, Huerta R. Hypocretin (orexin) regulation of sleep-to-wake transitions. Front Pharm. 2014:5:16.

157. Tsunematsu T, Kilduff TS, Boyden ES, Takahashi S, Tominaga M, Yamanaka A. Acute optogenetic silencing of orexin/hypocretin neurons induces slow-wave sleep in mice. J Neurosci. 2011;31:10529-39.

158. Sasaki K, Suzuki M, Mieda M, Tsujino N, Roth B, Sakurai T. Pharmacogenetic modulation of orexin neurons alters sleep/wakefulness states in mice. PLoS ONE. 2011;6:e20360.

159. Lawrence AJ, Cowen MS, Yang HJ, Chen F, Oldfield B. The orexin system regulates alcohol-seeking in rats. Br J Pharm. 2006;148:752-9.

160. Jupp B, Krivdic B, Krstew E, Lawrence AJ. The orexin ${ }_{1}$ receptor antagonist SB334867 dissociates the motivational properties of alcohol and sucrose in rats. Brain Res. 2011;1391:54-59.

161. Murillo-Rodriguez E, Arias-Carrion O, Zavala-Garcia A, Sarro-Ramirez A, HuitronResendiz S, Arankowsky-Sandoval G. Basic sleep mechanisms: an integrative review. Cent Nerv Syst Agents Med Chem. 2012;12:38-54.

162. Nelson LE, Lu J, Guo T, Saper CB, Franks NP, Maze M. The a2-adrenoceptor agonist dexmedetomidine converges on an endogenous sleep-promoting pathway to exert its sedative effects. Anesthesiology. 2003;98:428-36.

163. Mizuki Y, Suetsugi M, Ushijima I, Yamada M. Differential effects of noradrenergic drugs on anxiety and arousal in healthy volunteers with high and low anxiety. Prog Neuropsychopharmacol Biol Psychiatry. 1996;20:1353-67.

164. Shouse MN, Staba RJ, Saquib SF, Farber PR. Monoamines and sleep: microdialysis findings in pons and amygdala. Brain Res. 2000;860:181-9.

165. Park SP. In vivo microdialysis measures of extracellular norepinephrine in the rat amygdala during sleep-wakefulness. J Korean Med Sci. 2002;17:395-9.

166. Caballero A, De Andres I. Unilateral lesions in locus coeruleus area enhance paradoxical sleep. Electro Clin Neurophysiol. 1986;64:339-46.

167. Delfs JM, Zhu Y, Druhan JP, Aston-Jones G. Noradrenaline in the ventral forebrain is critical for opiate withdrawal-induced aversion. Nature. 2000:403:430-4. 
168. Koob GF, Schulkin J. Addiction and stress: an allostatic view. Neurosci Biobehav Rev 2019; https://doi.org/10.1016/j.neubiorev.2018.09.008

169. Spiegel K, Leproult R, Van Cauter E. Impact of sleep debt on metabolic and endocrine function. Lancet. 1999;354:1435-9.

170. Rodenbeck A, Hajak G. Neuroendocrine dysregulation in primary insomnia. Rev Neurol. 2001;157:S57-S61.

171. Vgontzas AN, Bixler EO, Lin HM, Prolo P, Mastorakos G, Vela-Bueno A, et al. Chronic insomnia is associated with nyctohemeral activation of the hypothalamic-pituitary-adrenal axis: clinical implications. J Clin Endocrinol Metab. 2001;86:3787-94.

172. Chrousos G, Vgontzas AN, Kritikou I. HPA axis and sleep. In: Feingold KR, Anawalt B, Boyce A, Chrousos G, Dungan K, Grossman A, Hershman JM, Kaltsas G, Koch C, Kopp P, Korbonits M, McLachlan R, Morley JE, New M, Perreault L, Purnell J, Rebar R, Singer F, Trence DL, Vinik A, Wilson DP, eds. Endotext. South Dartmouth, MA: MDText.com, Inc.; 2016. http://www.ncbi.nlm.nih.gov/books/ NBK279071/

173. Chrousos GA, Kattah JC, Beck RW, Cleary PA. Side effects of glucocorticoid treatment: experience of the Optic Neuritis Treatment Trial. JAMA 1993;269:2110-2.

174. Vgontzas AN, Pejovic S, Zoumakis E, Lin HM, Bixler EO, Basta M, et al. Daytime napping after a night of sleep loss decreases sleepiness, improves performance, and causes beneficial changes in cortisol and interleukin- 6 secretion. Am J Physiol Endocrinol Metab. 2007;292:E253-E261.

175. Gillin JC, Jacobs LS, Fram DH, Snyder F. Acute effect of a glucocorticoid on normal human sleep. Nature. 1972;237:398-9.

176. Born J, Späth-Schwalbe E, Schwakenhofer H, Kern W, Fehm HL. Influences of corticotropin-releasing hormone, adrenocorticotropin, and cortisol on sleep in normal man. J Clin Endocrinol Metab. 1989;68:904-11.

177. Ehlers CL, Reed TK, Henriksen SJ. Effects of corticotropin-releasing factor and growth hormone-releasing factor on sleep and activity in rats. Neuroendocrinology. 1986;42:467-74.

178. Hirotsu C, Tufik S, Andersen ML. Interactions between sleep, stress, and metabolism: from physiological to pathological conditions. Sleep Sci. 2015;8:143-52.

179. Antoni FA. Hypothalamic control of adrenocorticotropin secretion: advances since the discovery of 41-residue corticotropin-releasing factor. Endocr Rev. 1986;7:351-78.

180. de Vries GJ, Miller MA. Anatomy and function of extrahypothalamic vasopressin systems in the brain. Prog Brain Res. 1998;119:3-20.

181. Spath-Schwalbe E, Uthgenannt D, Körting N, Fehm HL, Born J. Sleep and wakefulness affect the responsiveness of the pituitary-adrenocortical axis to arginine vasopressin in humans. Neuroendocrinology. 1994;60:544-8.

182. Edwards S, Guerrero M, Ghoneim OM, Roberts E, Koob GF. Evidence that vasopressin $\mathrm{V} 1 \mathrm{~b}$ receptors mediate the transition to excessive drinking in ethanol-dependent rats. Addict Biol. 2012;17:76-85.

183. Achur RN, Freeman WM, Vrana KE. Circulating cytokines as biomarkers of alcohol abuse and alcoholism. J Neuroimmune Pharm. 2010;5:83-91.

184. Jewett KA, Krueger JM. Humoral sleep regulation: interleukin-1 and tumor necrosis factor. Vitam Horm. 2012;89:241-57.

185. Krueger JM, Majde JA. Microbial products and cytokines in sleep and fever regulation. Crit Rev Immunol. 1994;14:355-79.

186. Imeri L, Opp MR. How (and why) the immune system makes us sleep. Nat Rev Neurosci. 2009;10:199-210.

187. De Sarro G, Gareri P, Sinopoli VA, David E, Rotiroti D. Comparative, behavioural and electrocortical effects of tumor necrosis factor-a and interleukin-1 microinjected into the locus coeruleus of rat. Life Sci. 1997;60:555-64.

188. Manfridi A, Brambilla D, Bianchi S, Mariotti M, Opp MR, Imeri L. Interleukin-1 $\beta$ enhances non-rapid eye movement sleep when microinjected into the dorsal raphe nucleus and inhibits serotonergic neurons in vitro. Eur J Neurosci. 2003;18:1041-9.

189. Alam MN, McGinty D, Bashir T, Kumar S, Imeri L, Opp MR, et al. Interleukin-1 $\beta$ modulates state-dependent discharge activity of preoptic area and basal forebrain neurons: role in sleep regulation. Eur J Neurosci. 2004;20:207-16.

190. Kubota T, Li N, Guan Z, Brown RA, Krueger JM. Intrapreoptic microinjection of TNF- $a$ enhances non-REM sleep in rats. Brain Res. 2002;932:37-44.

191. Taishi P, Churchill L, Wang M, Kay D, Davis CJ, Guan X, et al. TNFa siRNA reduces brain TNF and EEG delta wave activity in rats. Brain Res. 2007;1156:125-32.

192. Obal F Jr, Opp M, Cady AB, Johannsen L, Postlethwaite AE, Poppleton HM, et al. Interleukin $1 \alpha$ and an interleukin $1 \beta$ fragment are somnogenic. Am J Physiol. 1990;259:R439-R446.

193. Gudewill S, Pollmächer T, Vedder H, Schreiber W, Fassbender K, Holsboer F. Nocturnal plasma levels of cytokines in healthy men. Eur Arch Psychiatry Clin Neurosci. 1992;242:53-56.

194. Covelli V, D'Andrea L, Savastano S, Valentino R, Tommaselli AP, Selleri A, et al. Interleukin-1 $\beta$ plasma secretion during diurnal spontaneous and induced sleeping in healthy volunteers. Acta Neurol. 1994;16:79-86.
195. Vgontzas AN, Papanicolaou DA, Bixler EO, Lotsikas A, Zachman K, Kales A, et al. Circadian interleukin-6 secretion and quantity and depth of sleep. J Clin Endocrinol Metab. 1999;84:2603-7.

196. Irwin MR, Olmstead R, Valladares EM, Breen EC, Ehlers CL. Tumor necrosis factor antagonism normalizes rapid eye movement sleep in alcohol dependence. Biol Psychiatry. 2009;66:191-5.

197. Breese GR, Knapp DJ, Overstreet DH, Navarro M, Wills TA, Angel RA. Repeated lipopolysaccharide (LPS) or cytokine treatments sensitize ethanol withdrawalinduced anxiety-like behavior. Neuropsychopharmacology. 2008;33:867-76. [erratum: 2008;33(7): 1777]

198. Knapp DJ, Whitman BA, Wills TA, Angel RA, Overstreet DH, Criswell HE, et al. Cytokine involvement in stress may depend on corticotrophin releasing factor to sensitize ethanol withdrawal anxiety. Brain Behav Immun. 2011;25: S146-S154. (Suppl 1)

199. Pava MJ, Woodward JJ. A review of the interactions between alcohol and the endocannabinoid system: implications for alcohol dependence and future directions for research. Alcohol. 2012;46:185-204.

200. Dyzma M, Boudjeltia KZ, Faraut B, Kerkhofs M. Neuropeptide $Y$ and sleep. Sleep Med Rev. 2010;14:161-5.

201. Zini I, Merlo Pich E, Fuxe K, Lenzi PL, Agnati LF, Härfstrand A, et al. Actions of centrally administered neuropeptide $Y$ on EEG activity in different rat strains and in different phases of their circadian cycle. Acta Physiol Scand. 1984;122:71-77.

202. Fuxe K, Agnati LF, Härfstrand A, Zini I, Tatemoto K, Pich EM, et al. Central administration of neuropeptide $\mathrm{Y}$ induces hypotension bradypnea and EEG synchronization in the rat. Acta Physiol Scand. 1983;118:189-92.

203. Szentirmai E, Krueger JM. Central administration of neuropeptide $Y$ induces wakefulness in rats. Am J Physiol Regul Integr Comp Physiol. 2006;291: R473-R480.

204. Toth A, Hajnik T, Záborszky L, Détári L. Effect of basal forebrain neuropeptide $Y$ administration on sleep and spontaneous behavior in freely moving rats. Brain Res Bull. 2007;72:293-301.

205. Antonijevic IA, Murck H, Bohlhalter S, Frieboes RM, Holsboer F, Steiger A Neuropeptide $\mathrm{Y}$ promotes sleep and inhibits ACTH and cortisol release in young men. Neuropharmacology. 2000;39:1474-81.

206. Heilig M, Koob GF, Ekman R, Britton KT. Corticotropin-releasing factor and neuropeptide $Y$ : role in emotional integration. Trends Neurosci. 1994;17:80-85.

207. Murillo-Rodriguez E. The role of the CB1 receptor in the regulation of sleep. Prog Neuropsychopharmacol Biol Psychiatry. 2008;32:1420-7.

208. Moreton JE, Davis WM. Electroencephalographic study of the effects of tetrahydrocannabinols on sleep in the rat. Neuropharmacology. 1973;12:897-907.

209. Pivik RT, Zarcone V, Dement WC, Hollister LE. $\Delta^{9}$-tetrahydrocannabinol and synhexl: effects on human sleep patterns. Clin Pharm Ther. 1972;13:426-35.

210. Santucci V, Storme JJ, Soubrié $P$, Le Fur G. Arousal-enhancing properties of the CB1 cannabinoid receptor antagonist SR $141716 \mathrm{~A}$ in rats as assessed by electroencephalographic spectral and sleep-waking cycle analysis. Life Sci. 1996;58: PL103-PL110.

211. Murillo-Rodriguez E, Blanco-Centurion C, Sanchez C, Piomelli D, Shiromani PJ. Anandamide enhances extracellular levels of adenosine and induces sleep: an in vivo microdialysis study. Sleep. 2003;26:943-7.

212. Murillo-Rodriguez $E$ ， Sánchez-Alavez $M$ ，Navarro $L$, Martínez-González $D$, Drucker-Colín R, Prospéro-García O. Anandamide modulates sleep and memory in rats. Brain Res. 1998;812:270-4.

213. Pava MJ, den Hartog CR, Blanco-Centurion C, Shiromani PJ, Woodward J. Endocannabinoid modulation of cortical up-states and NREM sleep. PLoS One. 2014;9:e88672

214. Fortin DA, Levine ES. Differential effects of endocannabinoids on glutamatergic and GABAergic inputs to layer 5 pyramidal neurons. Cereb Cortex. 2007;17:163-74

215. Cippitelli A, Cannella N, Braconi S, Duranti A, Tontini A, Bilbao A, et al. Increase of brain endocannabinoid anandamide levels by FAAH inhibition and alcohol abuse behaviours in the rat. Psychopharmacol 2008;198: 449-60 Errat- : Psychopharmacol. 2011;216:151

216. Serrano A, Rivera P, Pavon FJ, Decara J, Suárez J, Rodriguez de Fonseca F, et al. Differential effects of single versus repeated alcohol withdrawal on the expression of endocannabinoid system-related genes in the rat amygdala. Alcohol Clin Exp Res. 2012;36:984-94.

217. Fuller PM, Sherman D, Pedersen NP, Saper CB, Lu J. Reassessment of the structural basis of the ascending arousal system. J Comp Neurol. 2011;519:933-56.

218. Holst SC, Landolt HP. Sleep-wake neurochemistry. Sleep Med Clin 2018;13:137-46.

219. Clement O, Sapin E, Bérod A, Fort P, Luppi PH. Evidence that neurons of the sublaterodorsal tegmental nucleus triggering paradoxical (REM) sleep are glutamatergic. Sleep. 2011;34:419-23. 
220. Petit JM, Magistretti PJ. Regulation of neuron-astrocyte metabolic coupling across the sleep-wake cycle. Neuroscience. 2016;323:135-56.

221. Jones BE. Principal cell types of sleep-wake regulatory circuits. Curr Opin Neurobiol. 2017;44:101-9.

222. Xu M, Chung S, Zhang S, Zhong P, Ma C, Chang WC, et al. Basal forebrain circuit for sleep-wake control. Nat Neurosci. 2015;18:1641-7.

223. Anaclet C, Pedersen NP, Ferrari LL, Venner A, Bass CE, Arrigoni E, et al. Basal forebrain control of wakefulness and cortical rhythms. Nat Commun. 2015;6:8744.

224. Tabakoff B, Hoffman PL. Ethanol, sedative hypnotics, and glutamate receptor function in brain and cultured cells. Behav Genet. 1993;23:231-6.

225. Littleton JM, Lovinger D, Liljequist S, Ticku R, Matsumoto I, Barron S. Role of polyamines and NMDA receptors in ethanol dependence and withdrawal. Alcohol Clin Exp Res. 2001;25:132S-136S. (5 Suppl ISBRA)

226. Scofield MD, Heinsbroek JA, Gipson CD, Kupchik YM, Spencer S, Smith AC, et al. The nucleus accumbens: mechanisms of addiction across drug classes reflect the importance of glutamate homeostasis. Pharm Rev. 2016;68:816-71.

227. Hauri PJ, Olmstead EM. Reverse first night effect in insomnia. Sleep. 1989;12:97-105.

228. McCall C, McCall WV. Objective vs. subjective measurements of sleep in depressed insomniacs: first night effect or reverse first night effect? J Clin Sleep Med. 2012;8:59-65.

229. American Academy of Sleep Medicine. International Classification of Sleep Disorders. 3rd ed. Darien: American Academy of Sleep Medicine; 2014.

230. Bastien $\mathrm{CH}$, Vallières $\mathrm{A}$, Morin $\mathrm{CM}$. Validation of the Insomnia Severity Index as an outcome measure for insomnia research. Sleep Med. 2001;2:297-307.

231. Ford DE, Kamerow DB. Epidemiologic study of sleep disturbances and psychiatric disorders: an opportunity for prevention? JAMA. 1989;262:1479-84.

232. Weissman MM, Greenwald S, Niño-Murcia G, Dement WC. The morbidity of insomnia uncomplicated by psychiatric disorders. Gen Hosp Psychiatry. 1997:19:245-50.

233. Breslau N, Roth T, Rosenthal L, Andreski P. Sleep disturbance and psychiatric disorders: a longitudinal epidemiological study of young adults. Biol Psychiatry. 1996;39:411-8.

234. Brower KJ. Assessment and treatment of insomnia in adult patients with alcohol use disorders. Alcohol. 2015;49:417-27.

235. Brooks AT, Krumlauf M, Fryer CS, Beck KH, Yang L, Ramchandani VA, et al. Critical 7transitions: a mixed methods examination of sleep from inpatient alcohol rehabilitation treatment to the community. PLOS ONE. 2016;11: e0161725.

236. Brower KJ, Krentzman A, Robinson EA. Persistent insomnia, abstinence, and moderate drinking in alcohol-dependent individuals. Am J Addict. 2011b;20:435-40.

237. Gillin JC, Smith TL, Irwin M, Butters N, Demodena A, Schuckit M. Increased pressure for rapid eye movement sleep at time of hospital admission predicts relapse in nondepressed patients with primary alcoholism at 3-month followup. Arch Gen Psychiatry. 1994;51:189-97.

238. Kolla BP, Schneekloth T, Biernacka J, Mansukhani M, Geske J, Karpyak V, et al. The course of sleep disturbances in early alcohol recovery: an observational cohort study. Am J Addict. 2014:23:21-26.

239. Roberts RE, Roberts CR, Duong HT. Chronic insomnia and its negative consequences for health and functioning of adolescents: a 12-month prospective study. J Adolesc Health. 2008:42:294-302.

240. Kenney SR, LaBrie JW, Hummer JF, Pham AT. Global sleep quality as a moderator of alcohol consumption and consequences in college students. Addict Behav. 2012;37:507-12.

241. Miller MB, DiBello AM, Lust SA, Carey MP, Carey KB. Adequate sleep moderates the prospective association between alcohol use and consequences. Addict Behav. 2016;63:23-28.

242. Goodhines PA, Zaso MJ, Gellis LA, Park A. Sleep-related functional impairment as a moderator of risky drinking and subsequent negative drinking consequences in college students. Addict Behav. 2019;93:146-53.

243. Hasler BP, Soehner AM, Clark DB. Sleep and circadian contributions to adolescent alcohol use disorder. Alcohol. 2015;49:377-87.

244. Hartwell EE, Bujarski S, Glasner-Edwards S, Ray LA. The association of alcohol severity and sleep quality in problem drinkers. Alcohol Alcohol. 2015;50:536-41.

245. Fucito LM, DeMartini KS, Hanrahan TH, Whittemore R, Yaggi HK, Redeker NS. Perceptions of heavy-drinking college students about a sleep and alcohol health intervention. Behav Sleep Med. 2015;13:395-411.

246. Fucito LM, DeMartini KS, Hanrahan TH, Yaggi HK, Heffern C, Redeker NS. Using sleep interventions to engage and treat heavy-drinking college students: a randomized pilot study. Alcohol Clin Exp Res. 2017;41:798-809.

247. Arnedt JT, Conroy DA, Armitage R, Brower KJ. Cognitive-behavioral therapy for insomnia in alcohol dependent patients: a randomized controlled pilot trial. Behav Res Ther. 2011a;49:227-33.
248. Currie SR, Clark S, Hodgins DC, El-Guebaly N. Randomized controlled trial of brief cognitive-behavioural interventions for insomnia in recovering alcoholics. Addiction. 2004;99:1121-32.

249. Litten RZ, Fertig JB, Falk DE, Ryan ML, Mattson ME, Collins JF, et al. A doubleblind, placebo-controlled trial to assess the efficacy of quetiapine fumarate $\mathrm{XR}$ in very heavy-drinking alcohol-dependent patients. Alcohol Clin Exp Res. 2012;36:406-16.

250. Friedmann PD, Rose JS, Swift R, Stout RL, Millman RP, Stein MD. Trazodone for sleep disturbance after alcohol detoxification: a double-blind, placebocontrolled trial. Alcohol Clin Exp Res. 2008;32:1652-60.

251. Currie SR, Clark S, Rimac S, Malhotra S. Comprehensive assessment of insomnia in recovering alcoholics using daily sleep diaries and ambulatory monitoring. Alcohol Clin Exp Res. 2003;27:1262-9.

252. Wong MM, Brower KJ, Fitzgerald HE, Zucker RA. Sleep problems in early childhood and early onset of alcohol and other drug use in adolescence. Alcohol Clin Exp Res. 2004;28:578-87.

253. Wong MM, Robertson GC, Dyson RB. Prospective relationship between poor sleep and substance-related problems in a national sample of adolescents. Alcohol Clin Exp Res. 2015;39:355-62.

254. Johnson EO, Roehrs T, Roth T, Breslau N. Epidemiology of alcohol and medication as aids to sleep in early adulthood. Sleep. 1998;21:178-86.

255. Kaneita Y, Uchiyama M, Takemura S, Yokoyama E, Miyake T, Harano S, et al. Use of alcohol and hypnotic medication as aids to sleep among the Japanese general population. Sleep Med. 2007;8:723-32.

256. Krystal AD, Thakur M, Roth T. Sleep disturbance in psychiatric disorders: effects on function and quality of life in mood disorders, alcoholism, and schizophrenia. Ann Clin Psychiatry. 2008;20:39-46.

257. Mason BJ, Heyser CJ. Acamprosate: a prototypic neuromodulator in the treatment of alcohol dependence. CNS Neurol Disord Drug Targets. 2010:9:23-32.

258. Mason BJ, Goodman AM, Chabac S, Lehert P. Effect of oral acamprosate on abstinence in patients with alcohol dependence in a double-blind, placebocontrolled trial: the role of patient motivation. J Psychiatr Res. 2006:40:383-93.

259. Boeijinga PH, Parot P, Soufflet L, Landron F, Danel T, Gendre I, et al. Pharmacodynamic effects of acamprosate on markers of cerebral function in alcoholdependent subjects administered as pretreatment and during alcohol abstinence. Neuropsychobiology. 2004;50:71-77.

260. Staner L, Boeijinga P, Danel T, Gendre I, Muzet M, Landron F, et al. Effects of acamprosate on sleep during alcohol withdrawal: a double-blind placebo-controlled polysomnographic study in alcohol-dependent subjects. Alcohol Clin Exp Res. 2006;30:1492-9.

261. Perney $P$, Lehert $P$, Mason BJ. Sleep disturbance in alcoholism: proposal of a simple measurement, and results from a 24-week randomized controlled study of alcohol-dependent patients assessing acamprosate efficacy. Alcohol Alcohol. 2012;47:133-9.

262. Anton RF, Myrick H, Wright TM, Latham PK, Baros AM, Waid LR, et al. Gabapentin combined with naltrexone for the treatment of alcohol dependence. Am J Psychiatry. 2011;168:709-17.

263. Johnson BA, Rosenthal N, Capece JA, Wiegand F, Mao L, Beyers K, et al. Topiramate for treating alcohol dependence: a randomized controlled trial. JAMA. 2007;298:1641-51.

264. Johnson BA, Rosenthal N, Capece JA, Wiegand F, Mao L, Beyers K, et al. Improvement of physical health and quality of life of alcohol-dependent individuals with topiramate treatment: US multisite randomized controlled trial. Arch Intern Med. 2008;168:1188-99.

265. Mason BJ, Quello S, Goodell V, Shadan F, Kyle M, Begovic A. Gabapentin treatment for alcohol dependence: a randomized clinical trial. JAMA Intern Med. 2014;174:70-77.

266. Furieri FA, Nakamura-Palacios EM. Gabapentin reduces alcohol consumption and craving: a randomized, double-blind, placebo-controlled trial. J Clin Psychiatry. 2007;68:1691-1700.

267. Karam-Hage M, Brower KJ. Gabapentin treatment for insomnia associated with alcohol dependence. Am J Psychiatry. 2000;157:151.

268. Brower KJ, Myra Kim H, Strobbe S, Karam-Hage MA, Consens F, Zucker RA. A randomized double-blind pilot trial of gabapentin versus placebo to treat alcohol dependence and comorbid insomdnia. Alcohol Clin Exp Res. 2008;32:1429-38.

269. Falk DE, Ryan ML, Fertig JB, Devine EG, Cruz R, Brown ES, et al. Gabapentin enacarbil extended-release for alcohol use disorder: a randomized, doubleblind, placebo-controlled, multisite trial assessing efficacy and safety. Alcohol Clin Exp Res. 2019;43:158-69.

270. Lawrence A, Bonomo Y. Suvorexant in the management comorbid sleep disorder and alcohol dependence [ClinicalTrials.gov Identifier no. NCT03897062]; 2019. https://clinicaltrials.gov/ct2/show/NCT03897062?term $=$ NCT03897062; accessed June 4, 2019 
Alcohol use disorder and sleep disturbances: a feed-forward allostatic... GF Koob and IM Colrain

271. Sullivan EV, Harris RA, Pfefferbaum A. Alcohol's effects on brain and behavior. Alcohol Res Health. 2010;33:127-43.

272. Zahr NM, Pfefferbaum A, Sullivan EV. Perspectives on fronto-fugal circuitry from human imaging of alcohol use disorders. Neuropharmacology. 2017; 122:189-200.

273. Gee NS, Brown JP, Dissanayake VUK, Offord J, Thurlow R, Woodruff GN. The novel anticonvulsant drug, gabapentin (Neurontin), binds to the a $\delta$ subunit of a calcium channel. J Biol Chem. 1996;271:5768-76.

274. Hoyer D, Jacobson LH. Orexin in sleep, addiction and more: is the perfect insomnia drug at hand? Neuropeptides 2013;47:477-88.

275. Campbell EJ, Marchant NJ, Lawrence AJ. A sleeping giant: suvorexant for the treatment of alcohol use disorder? Brain Res 2018; https://doi.org/10.1016/j. brainres.2018.08.005

276. Kuriyama A, Tabata $H$. Suvorexant for the treatment of primary insomnia: a systematic review and meta-analysis. Sleep Med Rev. 2017;35:1-7.

277. Gentile TA, Simmons SJ, Barker DJ, Shaw JK, España RA, Muschamp JW. Suvorexant, an orexin/hypocretin receptor antagonist, attenuates motivational and hedonic properties of cocaine. Addict Biol. 2018;23:247-55.

278. Grosshans M, Mutschler J, Luderer M, Mann K, Kiefer F. Agomelatine is effective in reducing insomnia in abstinent alcohol-dependent patients. Clin Neuropharmacol. 2014;37:6-8.

279. Gann H, Feige B, Cloot O, Van Wasen H, Zinzgraf D, Hohagen F, et al. Polysomnography during withdrawal with clomethiazole or placebo in alcohol dependent patients-a double-blind and randomized study. Pharmacopsychiatry. 2004a;37:228-35.
280. Karam-Hage M, Brower KJ. Open pilot study of gabapentin versus trazodone to treat insomnia in alcoholic outpatients. Psychiatry Clin Neurosci. 2003;57:542-4.

281. Malcolm R, Myrick LH, Veatch LM, Boyle E, Randall PK. Self-reported sleep, sleepiness, and repeated alcohol withdrawals: a randomized, double blind, controlled comparison of lorazepam vs gabapentin. J Clin Sleep Med. 2007;3:24-32.

282. Chakravorty S, Hanlon AL, Kuna ST, Ross RJ, Kampman KM, Witte LM, et al. The effects of quetiapine on sleep in recovering alcohol-dependent subjects: a pilot study. J Clin Psychopharmacol. 2014;34:350-4.

283. Brower KJ, Conroy DA, Kurth ME, Anderson BJ, Stein MD. Ramelteon and improved insomnia in alcohol-dependent patients: a case series. J Clin Sleep Med. 2011a;7:274-5.

284. Le Bon O, Murphy JR, Staner L, Hoffmann G, Kormoss N, Kentos M, et al. Doubleblind, placebo-controlled study of the efficacy of trazodone in alcohol postwithdrawal syndrome: polysomnographic and clinical evaluations. J Clin Psychopharmacol. 2003;23:377-83.

285. Fabre LF Jr, Gainey A, Kemple S, McLendon DM, Metzler CM. Pilot open-labe study of triazolam in the treatment of insomnia following alcohol withdrawal. J Stud Alcohol. 1977;38:2188-92.

286. Greeff AP, Conradie WS. Use of progressive relaxation training for chronic alcoholics with insomnia. Psychol Rep. 1998:82:407-12.

287. Arnedt JT, Conroy D, Rutt J, Aloia MS, Brower KJ, Armitage R. An open trial of cognitive-behavioral treatment for insomnia comorbid with alcohol dependence. Sleep Med. 2007b;8:176-80. 